\title{
GETTING A GRIP ON THE SADDLE: CHASMS OR CYCLES?
}

\section{Deepa Chandrasekaran}

\author{
Gerard J. Tellis
}

Deepa Chandrasekaran is an Assistant Professor at Lehigh University, 621 Taylor St., Bethlehem, PA (Email : dec207@lehigh.edu, Tel: 610-758-6582 ) and Gerard J. Tellis is Director of Center for Global Innovation, Neely Chair of American Enterprise, and Professor of Marketing at the Marshall School of Business, University of Southern California, Los Angeles, CA 90089. (Email: tellis@usc.edu; Tel: 213-740-5031).

The authors thank Gary Frazier and the participants of a doctoral seminar at the University of Southern California, participants at the Marketing Science Institute Conference at Los Angeles 2007, Marketing Science Conference 2006, the International Conference on Innovation, Chennai, S. Siddarth, Ashish Sood and Ram Ranganathan for their insightful comments on earlier versions. The authors acknowledge financial support from the USC Marshall Center for Global Innovation (sponsored by Don Murray), the USC Marshall Center for International Business Education Research (CIBEAR) and the Christian and Mary Lindback Foundation's Minority Junior Faculty award. 


\title{
GETTING A GRIP ON THE SADDLE: CHASMS OR CYCLES?
}

\begin{abstract}
The saddle is a sudden, sustained, and deep drop in sales of a new product, after a period of rapid growth following takeoff, followed by a gradual recovery to the former peak. This paper tests for the generalizability of the saddle across products and countries and for three rival explanations: chasms in adopter segments, business cycles, and technological cycles. The authors model both boundary points of the saddle: start of the sales drop and recovery to the initial peak, using split-population models. Empirical analysis of historical sales data from 10 products across 19 countries shows that the saddle is fairly pervasive. The onset of the saddle occurs in 148 product-country combinations. On average, the saddle occurs 9 years post-takeoff, at a mean penetration of $30 \%$, lasting for 8 years with a $29 \%$ drop in sales at its depth. Results support explanations of chasms and technological cycles for information/entertainment products and business cycles and technological cycles for kitchen/laundry products. The authors discuss findings, contributions, and implications.

Keywords: New product diffusion, International marketing, Chasm, Business cycles, Hazard models
\end{abstract}


A "saddle" is a phenomenon characterized by a sudden, sustained, and deep drop in sales of a new product, after a period of rapid growth following takeoff, followed by a gradual recovery to the former peak (Figures 1 and 2). Recent papers empirically document this phenomenon of a trough in sales. For example, Goldenberg, Libai and Muller (2002) find a saddle in up to $50 \%$ of 32 consumer electronics products in the US. Golder and Tellis (2004) define a "slowdown" (or start of the saddle) as the end of the growth phase in a product's life cycle and find that the slowdown occurs in $96 \%$ of a sample of 23 products within the US.

Empirical support for the saddle is based on studies using only U.S. data. Is the phenomenon generalizable across countries? Researchers also propose differing explanations for the saddle. Goldenberg, Libai and Muller (2002) emphasize the role of chasms in adopter segments; while they note that changes in technology or macroeconomic events may lead to the saddle, they do not empirically test these explanations. Golder and Tellis (2004) emphasize the role of negative cascades, which they measure as change in GNP.

As Hauser, Tellis and Griffin (2006) note, the limited empirical evidence and differing explanations for the saddle underscore the need to thoroughly document and explain this phenomenon across a wider cross section of countries and products. Because a saddle involves a sudden and sharp decline in sales that were previously increasing rapidly, accurately testing its generalizability and understanding its drivers has far-reaching managerial implications. Such declines may have adverse consequences for managers of new products, who may have overcommitted manufacturing capacity, built large inventories, or expanded their sales staff during the period of growth. Worse still, if they believe the phenomenon to be permanent to their product, they may drastically reduce capacity, inventory, or staff, and suffer from missed orders and sales once the growth resumes. 
This study aims to develop a better understanding of the phenomenon of the saddle. In particular, it seeks answers to three questions:

1) How pervasive is the saddle across countries and categories?

2) What are the characteristics of the saddle in terms of start, depth, and duration of decline?

3) What theories explain the saddle?

4) Can a model predict a saddle?

The next section discusses rival theories of the saddle. The subsequent three sections present the method, results, and discussion.

\section{Rival Theories of the Saddle}

This section first defines the terms in use and then discusses three alternate theories or causes of the saddle that have been proposed in the prior literature: chasms in adopter segments, economic cycles, and technological cycles.

\section{Definitions}

A "product" refers to a group of brands that are close substitutes and fulfill a distinct need from the consumer's viewpoint (Golder and Tellis 2004), for example, DVD players. We use the term "product-country combination" to refer to a specific product in a specific country. The term "sales" refer to the total of all consumer purchases of all brands of a specific product.

"Takeoff" is defined as a dramatic increase in sales that marks the transition from the introduction stage to the growth stage of the product life cycle (Agarwal and Bayus 2002; Golder and Tellis 1997). Linking the phenomenon of the saddle to the concept of takeoff has two advantages. First, we avoid considering products that did not make it to a mass market, i.e., that simply failed. Second, it can help distinguish characteristics of the saddle relative to takeoff. 
We further define two boundary points of the saddle: start and recovery: The "start of the saddle" is the first year of decreasing product sales and "recovery" is the first year in which sales cross the prior initial peak.

\section{Chasms in Adopter Segments}

The product life cycle is viewed as a social phenomenon, driven primarily by communication processes that transfer new product information between members of a social system (Golder and Tellis 2004). Rogers (1995) classifies product adopters into five distinct groups (innovators, early adopters, early majority, late majority and laggards) based on the normal penetration curve. The traditional view has been that the diffusion process can be fuelled by simply targeting the innovators and the early majority, thereby triggering an unbroken wordof- mouth communication process across other adopter segments (Mahajan and Muller 1998; Rogers 1995).

However, some researchers debate this notion of continuity in the communication process (Goldenberg, Libai and Muller 2002; Mahajan and Muller 1998; Moore 1991; Van den Bulte and Joshi 2007). Moore (1991) suggests that "cracks in the bell curve" may exist between different groups of adopters in the case of high technology products. According to Moore, the biggest crack, or a "chasm" separates the early adopters from the early majority (Figure 3). The early adopters and the early majority possess very different characteristics and needs. Hence the former do not form a good word of mouth reference point for the latter. Van den Bulte and Joshi (2007) point out one implication of this theory that product offerings appealing to technology enthusiasts need not appeal to the mainstream market; hence mainstream customers discount adoptions by technology enthusiasts and care only about adoptions by other mainstream customers. Goldenberg, Libai and Muller (2002) classify adopter segments as early market and 
main market based on the timing of adoption of a new product. They argue that weak communication between the early market and the main market may lead these segments to adopt products at substantially differing rates, that is, the main market takes off after the early market peaks, thus creating a saddle (Figure 4, adapted from Goldenberg, Libai and Muler 2002). Following this logic, the literature suggests the following hypotheses:

Alternative: $\mathrm{H}_{\mathrm{A} 1}$ : A saddle is likely to occur during a discontinuity in the transition between the early and late markets (or a chasm).

We test this hypothesis again the null hypothesis:

Null: $\mathrm{H}_{01}$ : There is no association between a discontinuity in the transition between the early and late markets (or a chasm) and a saddle.

\section{Business Cycles}

Prior marketing research has concentrated on the positive impact of income changes on product diffusion (Golder and Tellis 1998; Talukdar, Sudhir and Ainslie 2002). However, prior research has not studied the differences between the effect of economic contractions on sales of information/entertainment and kitchen/laundry products. Recently, researchers have shown the impact of business cycles on the sales of consumer durables (Deleersnyder et al 2004), growth of private labels (Lamey et al 2007), and role of marketing strategy (Srinivasan, Rangaswamy and Lilien 2005). In the excitement of post-takeoff growth, managers may believe that their new product's sales will be immune to economic contractions and continue to grow. However, a saddle may start even in the growth stage due to economic contractions. For instance, Figure 5 shows the sales of dishwashers (denoted by the dotted line) and economic contractions (denoted by the dark bars) in Germany. Note, sales peak in 1973, and the saddle starts in 1974, coinciding with the economic contraction of 1974. 
The saddle may occur during periods of economic contractions for four reasons: First, an economic contraction shrinks income and depresses buying power. As a result, consumers are likely to cut back on discretionary expenditure, such as purchases of consumer durables. Second, consumers may lose trust during a contraction more quickly than they gain confidence during the ensuing expansion, leading to cyclical asymmetries in the purchase of durables (Deleersnyder et al 2004; Lamey et al 2007). Third, firms engage in cyclical marketing strategies, such as cutting advertising expenditures (Deleersnyder et al 2004; Lamey et al 2007) or investments (Mascarenhas and Aaker 1989) during contractions. These actions may further aggravate the decline in sales during a contraction. Fourth, the onset of a recession may trigger a negative cascade in new product sales. If a positive cascade first triggers a run-up in sales, when faced with a recession, some consumers may decide to wait before purchasing the new product. When other consumers become aware of these decisions, a negative cascade may begin, triggering a sharp drop in sales at the onset of maturity (Golder and Tellis 2004).

The above reasons point to a strong but previously ignored driver of the saddle in new product sales: economic contractions. This reasoning suggests the following testable hypothesis:

$\mathrm{H}_{2}$ : A saddle is likely to occur during periods of economic contractions.

\section{Technological Cycles}

Consumers' beliefs about the significance or size of anticipated improvements in technology may influence new product sales (Balcer and Lippman 1984; Holak et al 1987; Doyle and Saunders 1985). John, Weiss and Dutta (1999) argue that while significant improvements may prompt purchases once they arrive, they may have a chilling effect when they are expected imminently. Consumers may be uncertain about the nature and extent of the technological change and decide to wait and watch (John, Weiss and Dutta 1999) or may leapfrog a product 
generation in expectation of product improvements or price declines (Goldenberg, Libai and Muller 2002; Weiss 1994). Further, Van den Bulte and Stremersch (2004) propose that when faced with multiple competing standards, even innovative consumers may postpone adoption until the uncertainty about what standard will dominate has been resolved. Doyle and Saunders (1985) say that such anticipatory effects may cause even retailers to hold off their purchases in anticipation of changes. Hence, we may expect a saddle to start during times of multiple important technological advances, due to uncertainty in the minds of consumers and retailers. This theory points to a strong but empirically untested driver of the saddle in new product sales: technological advances. The above argument suggests the following testable hypothesis: $\mathrm{H}_{3}$ : A saddle is likely to occur during times of important technological advances.

\section{Method}

This section describes the model, measures, and data sources.

\section{Model}

Since the occurrence of the saddle is a time-dependent event with two boundary points, start of the saddle and recovery to initial peak, we model it using two separate split-population hazard models. Each hazard model captures one of the two boundary events. The standard hazard model explains the conditional probability that an individual i will experience an event in a time period t given it has not already occurred, as a function of a baseline hazard plus some explanatory variables (Singer and Willett 2003). In new product research, the hazard function has been used to analyze diffusion (Bass 1969) and hazard models have been used to predict takeoff (Agarwal and Bayus 2002; Chandrasekaran and Tellis 2008; Golder and Tellis 1997; Golder and Tellis 2004; Tellis, Stremersch and Yin 2003). 
The standard hazard model assumes that, every case eventually experiences the event (Prins and Verhoef 2007). However, a proportion of the cases may never actually observe the occurrence of the event. A split population hazard model allows for some cases never to experience the event (Schmidt and Witte 1989). For example, split population models have been used in the marketing literature to study the diffusion of automated teller machines (Sinha and Chandrashekaran 1992), the emergence of dominant designs (Srinivasan, Lilien and Rangaswamy 2005), and the adoption timing of a new e-service (Prins and Verhoef 2007).

The discrete-time specification of the hazard model allows for great flexibility in specifying the time function and for incorporating time-varying explanatory variables (Allison 1982; Allison 1995; Singer and Willett 1993). Jenkins (2001) outlines a procedure for a discretetime split population survival model, which enables us to incorporate time-varying covariates in a discrete time hazard framework, while taking into account the possibility that a proportion of the products may never experience the event (either the start of the saddle, or the recovery following the start of the saddle). We next describe the events and the split population formulations of the model.

Events. We model two events: 1) the start of saddle given takeoff and 2) the recovery given the start of saddle. The hazard of the start of a saddle is the probability that a productcountry combination, $\mathrm{i}$, experiences a start of the saddle in time, $\mathrm{t}$, given it has not done so yet but takeoff has occurred. The hazard of recovery is the probability that a product-country combination experiences a recovery to past the initial peak given it has not done so yet but the saddle has started.

Each product's history is broken into a set of distinct observations, one for each year, up to and including the year of the event or till the series gets censored. For each of these 
observations, the dependent variable takes on a value 1 if the event occurs during that time period, otherwise 0 . Explanatory variables take on whatever value occurs during that time period. For the proportion of products where we have observed the event, we have duration data that constitute a complete series. However, for the products where the event is not observed, the observations are interpreted as incomplete series, and are censored.

Split population formulation. Split population models assume that a proportion, c, never experience the event, and estimate this unobserved proportion. Let $\mathrm{A}_{\mathrm{i}}$ be an indicator of whether a product-country combination i eventually experiences the event or not, where $A_{i}=1$ means event occurrence and $A_{i}=0$ means the event never occurs. Let the probability of $\left(A_{i}=1\right)=1-c$ and the probability of $\left(\mathrm{A}_{\mathrm{i}}=0\right)=\mathrm{c}$.

For those product-country combinations where the event is observed during a given time interval, the contribution to the likelihood is $(1-c) *$ (probability of survival to end of previous time interval)*(probability of the event in the given interval). Censored observations consist of those that never observe the event plus those not yet observed to fail. Hence the contribution to the likelihood from a censored survival time is $c+(1-c) *$ (probability of survival to end of the given time interval).

Let $d_{i}$ be the observable binary censoring indicator indicating whether or not the $i^{\text {th }}$ product-country combination experiences the event in $(0, t)$, with $d_{i}=1$ if the event occurs and $d_{i}$ $=0$ if right-censored. We can then estimate by maximum likelihood the proportion of productcountry combinations which never experience the event, together with the parameters characterizing the hazard rate for the remainder of the population. Hence, the Likelihood contribution for product-country combination i with survival time $t$ is

$$
\ln L_{i}=d_{i} \cdot \ln \left[(1-c) \cdot\left(h_{i t}\right) \cdot\left(S_{i t-1}\right)\right]+\left(1-d_{i}\right) \ln \left[c+(1-c)\left(S_{i t}\right)\right]
$$


where $\mathrm{S}_{\mathrm{it}}$ is the discrete-time survivor function, and $\mathrm{h}_{\mathrm{it}}$ is the (complementary $\log -\log$ ) discrete-time hazard rate, expressed as

$$
\begin{aligned}
S_{i t} & =\prod_{j=1}^{t}\left(1-h_{i j}\right) \\
h_{i t} & =1-\exp \left[-\exp \left(D(t)+b X_{i t}\right)\right]
\end{aligned}
$$

Where $\mathrm{D}(\mathrm{t})$ summarizes the duration dependence in the hazard model common to each $\mathrm{i}$. We specify a flexible functional form of $\mathrm{D}(\mathrm{t})=\mathrm{t}+\mathrm{t}^{2}+\log (\mathrm{t})$, and later test the robustness of the analysis to the linear specification $\mathrm{D}(\mathrm{t})=\mathrm{t} . \mathrm{X}_{\mathrm{it}}$ consists of the independent variables and control variables, described in the next sub-section.

Hence, the hazard function consists of time-varying covariates, time-invariant covariates, as well as the effect of time. If $\mathrm{c}=0$, a testable hypothesis, the split population survival model reduces to the standard discrete-time proportional hazards model (or complementary log-log model). We use the STATA procedure SPSURV (Jenkins 2001) to estimate the model. The estimation procedure uses the maximum-likelihood complementary log-log model to derive starting values. The complementary log-log model is particularly useful when data from discrete time intervals are used to capture a continuous underlying process (Allison 1995; Prins and Verhoef 2007).

\section{Measures}

This section describes the measures to assess takeoff, the boundary points of saddle, chasms in adopter segments, economic cycles, technological cycles, and the control variables. Year of takeoff. We measure takeoff using the rule proposed by Tellis, Stremersch and Yin (2003), who define takeoff as the first year in which a product's growth rate relative to its previous year's unit sales is higher than the threshold for takeoff which is based on market penetration. 
Boundary points of the saddle. We operationalize the two boundary points of the saddle. The start of the saddle is the first year of a trough in sales following takeoff, where sales drop for at least two consecutive years to a depth of at least $10 \%$ from an initial peak. This rule ensures that we avoid modeling transient sales drops spuriously as a saddle. It also ensures consistency across products and countries. Our measure is similar to others proposed in the literature. For instance, Goldenberg, Libai and Muller (2002) operationalize the saddle as a trough following an initial peak in sales, reaching a depth of at least $20 \%$ of the peak (strict definition) or $10 \%$ of the peak (relaxed case), lasting at least two years, followed by sales that exceed the initial peak. Golder and Tellis (2004) measure slowdown (or start of the saddle) as the first year of two consecutive years, after takeoff, in which sales are lower than the peak of previous sales.

The end of the saddle, the recovery, is the first year following the start of a saddle, in which the sales surpasses the previous peak.

Chasm in adopter segments. As mentioned in the theory section, prior research has classified adopter categories based on the penetration curve (.e.g., Mahajan, Muller and Srivastava 1990; Mahajan and Muller 1998; Moore 1991; Muller and Yogev 2006; Rogers 1995). Muller and Yogev (2006) determine that in a dual-market setting, the main market outnumbers the early market at a penetration level that varies between $3 \%$ and $33 \%$ depending on the product. Because of this high variation, the point of chasm would vary by product category, though it is likely to be the same across countries. Indeed, prior research has shown that diffusion parameters are unique to particular products (e.g., see Chandrasekaran and Tellis 2007; Muller and Yogev 2006).

So, a mean penetration level, for each product, that reflects adoption by the early market and non-adoption by the late market, can serve as a proxy for the location of the chasm. However, 
theory is silent about the exact penetration percentage at which the chasm is likely to be located. To resolve this problem, we can take advantage of the fact that we have data across countries for each product. Based on the literature cited above we make the reasonable assumption that adopter segments are likely to be common across countries but unique for each product.

So, we first calculate from the data, the mean penetration in the year of the saddle across all countries, except the focal country, for each product ("meanpen"). Here, we use the information only from product-country combinations that experience the event. Next, we define a variable "dispersion" to capture the distance of the actual penetration in the year before for the target product-country combination from the mean penetration calculated in the previous step, as follows:

$$
\text { Dispersion }_{i t}=A b s\left(\text { Penetration }_{i t-1}-\text { Meanpen }\right)
$$

Note that we use penetration in the year before, and drop the focal country from the calculation of meanpen, to allay concerns that the measure is tautological. Hypothesis testing (e.g. Sawyer \& Peter, 1983), tests the probability of the data if the null hypothesis is true. Now, given that adopter categories are likely to persist across countries for a product, if the null were true, then the hazard of a saddle should not increase as distance from meanpen decreases. On the other hand, if the testing of this hypothesis results in a negative coefficient in the hazard model, that would lead us to reject the null and conclude in favor of the chasms theory captured by hypothesis $\mathrm{H}_{\mathrm{A} 1}$.

Business cycles. We construct a measure to capture economic contractions and expansions based on recent marketing literature (Deleersnyder et al. 2009; Deleersnyder et al. 2004; Lamey et al. 2007). These studies estimate business cycles by extracting the cyclical component from the GDP series, using the Hodrick and Prescott (1997) filter. The Hodrick and 
Prescott (HP) filter decomposes a time $y_{t}$ series into a trend component $l_{t}$, which varies smoothly over time and a cyclical component $\mathrm{c}_{\mathrm{t}}$, by fitting a smooth curve through a set of points defined by the log-transformed GDP series (Stock and Watson 1999). The HP filter first obtains the long term trend, and then obtains the cyclical component, which fluctuates around that trend, by subtracting the long-term trend from the original time series (Lamey et al. 2007). We use the software program EViews to estimate the cyclical component of the GDP series for each of the 19 countries, based on the HP filter.

We next create an indicator variable termed "economic contraction" for the state of the economy. We set this indicator variable to 1 , for decreases in the cyclical component of GDP corresponding to contractions. We set this indicator variable to 0 , for increases in the cyclical component of GDP corresponding to expansions. A positive coefficient for the measure of economic contraction in the hazard model would imply that a saddle is more likely during an economic contraction than during an economic expansion.

Technological cycles. We measure technological cycles using patenting activity. Patents have been used in prior research as an important indicator of technological activities and innovation in an industry (e.g., Ahuja and Katila 2001; Tellis, Prabhu and Chandy 2009). The US patent collection contains the list of all patents issued by the US Patent and Trademark Office (USPTO) since 1974. We consider US patents that have been granted to be a valid indicator of technological activity for the product across countries because most important innovations either originated in the US or the firms involved have filed US patents to protect this large market (Tellis, Prabhu and Chandy 2009). For each product, we extract all US patents from Delphion's patent database, sort the patents based on the Inventive IPC code, and retain patents that are most directly associated with the focal product. 
We have data on both the number of patents and the forward citations received by the patents for each product at each time period. Forward citations refer to the number of times the focal patent was cited by other patents. Trajtenberg (1990) finds a close association between citation-based patent indices and the social value of innovations from an empirical analysis of a particular innovation (Computed Tomography scanners). Further, Chandy et al (2006) argue that patent citations are a valid measure to capture important ideas because they are objective, readily available, and unlikely to be either inflated or understated. Hence, we use the patent citations as an index of the importance or value of the patents. We weight patent counts by this measure, as in Trajtenberg (1990), to create a measure "weighted patent counts" as follows.

$$
W P C_{t}=\sum_{j=1}^{n_{t}}\left(1+C_{j}\right)
$$

Where $\mathrm{n}_{\mathrm{t}}$ is the number of patents issued during the year $\mathrm{t}$ and $\mathrm{C}_{\mathrm{j}}$ is the number of forward citations received by a patent ' $\mathrm{j}$ ' for the product. This linear weighting scheme allows us to take into account both the number of citations and the count of patents.

A positive coefficient for this measure in the hazard model would indicate that an increase in technological activity is driving the start of the saddle.

Control variables. In a globalized world, consumers' adoption of new products may be influenced by not just communication behaviors among consumers and environment factors within a country but also by cross-national learning flows from lead markets (Ganesh and Kumar 1996; Putsis et al 1997; Takada and Jain 1991). Prior research has pointed out the presence of cross-country learning effects influencing the takeoff of new products (Chandrasekaran and Tellis 2008; Tellis, Stremersch and Yin 2003; Everdingen, Stremersch and Fok 2009). We control for cross-country learning effects, using "prior saddles", which is the number of saddles that occur in the previous year in other countries for each product. 
Prior research suggests that greater inter-connectivity, media penetration, demographic changes, and technology improvements encourage availability, awareness, and appeal of new products (Chandrasekaran and Tellis 2008; Van den Bulte 2000) and may lead to faster diffusion or takeoff of new products. On the one hand, this may create a cascade in sales for newly commercialized products, leading to an earlier or steeper saddle in sales. On the other hand, newly commercialized products may enjoy a sustained sales momentum, reducing or delaying the possibility of a saddle in sales. We operationalize "product vintage" as the first year in which an innovation was commercialized across all countries in the sample. Finally, we control for within-innovation duration dependence, by considering "product age", operationalized as the time elapsed since the product was commercialized in each country. Following Agarwal and Bayus (2002) and Chandrasekaran and Tellis (2008), we use the word "commercialization" to reflect the fact that databases seem to include a product only when it has become available to the mass market or achieved some minimal level of sales or penetration. We look for the earliest year of commercialization for each country from the sales and penetration data for each product in each country. We further validate each of these dates by checking that penetration in the year of commercialization has not exceeded $0.25 \%$, which is a stricter rule than the $0.5 \%$ rule recommended by Tellis, Stremersch and Yin (2003).

\section{Data and Sources}

We assemble a database on historical sales and market penetration of both kitchen/laundry products and information/entertainment products. We obtain data on 6 kitchen/laundry products (dishwashers, dryers, freezers, microwave ovens, refrigerators and washing machines) and 4 information/entertainment products (DVD players, PCs, VCRs, and video cameras). We track these products across 16 European countries (Austria, Belgium, 
Denmark, Finland, France, Germany, Greece, Italy, Ireland, Netherlands, Norway, Portugal, Spain, Sweden, Switzerland and U.K.), Japan, Canada and the US, from 1950 through 2008, for a total of over 1300 observations. For the U.S., in some cases, we had data extending before 1950. We put together this detailed time-series data, based on several hundred research hours, from a variety of sources: subscription-based sources (Euromonitor Global Marketing Information Database, World Development Indicators Online, Fast Facts Database from the Consumer Electronics Association), archival search of several secondary sources (Historical Statistics of Japan, Electrical Merchandising, Merchandising, Merchandising Week and Dealerscope journals for US, Consumer Europe, European Marketing Data and Statistics), and proprietary industry data.

We exclude product-country combinations for which we have less than 10 years of data. We also exclude product-country combinations for which the sales data in the first year exceeds 100 (in ' 000 s of units) or the penetration in the first year exceeds $0.5 \%$. For the US, we drop washing machines, where we do not have early enough data to estimate takeoff. As can be seen from Web Appendix W1, the scope of our study is larger than the majority of the prior studies on diffusion of new products, which have typically included either very few products or very few countries or very few combinations of both. The additional challenge in this paper was to obtain sales and penetration data. As such, this is the one of the largest studies that uses both sales and penetration data (See Web Appendix W1).

For calculating the time of economic contractions across countries, we use a measure for Real GDP from the Groningen Growth and Development Centre and the Conference Board, Total Economy Database, (http://www.ggdc.netis ). We use Total GDP, in millions of 1990 US\$ (converted at Geary Khamis PPPs). We determine GDP for the pre 1950 years from 
Statistics on World Population, GDP and per-capita GDP, 1-2006 AD

(www.ggdc.net/maddison ).We obtain patent data from the Delphion database. The Delphion database (www.delphion.com ) is a subscription-based database that contains detailed historical records on patents granted and applied for both in the US and other countries, and has been used in prior studies (e.g., Tellis, Prabhu and Chandy 2009).

\section{Results}

This section presents descriptive statistics, results of the estimation of the hazard models for start and recovery of saddle, and tests of robustness.

\section{Descriptive Statistics}

This section describes characteristics of the saddle and its convergence over time.

Characteristics of the saddle. Out of the 156 product-country combinations where takeoff has occurred, we observe the start of the saddle in 148 cases (99\% of the kitchen/laundry products and $88 \%$ of the information/entertainment products). These numbers are slightly lower than the 96\% reported in Golder and Tellis (2004), and similar to the 86\% reported by Goldenberg et al (2006). Out of the 148 product-country combinations that see the start of the saddle, 120 cases (81\%), experience a recovery to the previous peak. Both the start and a recovery are observed in $86 \%$ of kitchen/laundry products and $61 \%$ of information/entertainment products (Table 1). The numbers observed for the latter are somewhat higher than the 33-50\% reported in Goldenberg, Libai and Muller (2002). However, our sample is the most global of such studies.

$46 \%$ of the 156 products experience an average depth of $20 \%$ during the saddle, as well as see a recovery to the original peak. These include $45 \%$ of kitchen/laundry products and $47 \%$ 
of information/entertainment products. These numbers correspond to the strict definition of the saddle used in Goldenberg, Libai and Muller (2002).

We see censoring in some categories such as DVD players. In the censored cases, either the saddle may start at a later point in time or the saddle may never occur. The split hazard model can distinguish between these two possibilities.

Table 2 gives a description of the key statistics of timing, duration, and depth of the saddle. For the 148 products that experience the start of the saddle, the average time from takeoff to the start of the saddle is roughly 9 years. The average penetration at the start of the saddle is $31 \%$, which is similar to the $34 \%$ seen in Golder and Tellis (2004). The average time from takeoff to the start of the saddle is 6.7 years for information/entertainment products and 10.3 years for kitchen/laundry products. The average penetration at the start of the saddle is $26 \%$ for the information/entertainment products and $33 \%$ for kitchen/laundry products. The average decline in the first year of the saddle for information/entertainment products is $17 \%$ compared to $10 \%$ for kitchen/laundry products.

The duration of the saddle is the time from the start of the saddle to the recovery, when the sales grow past the initial peak. We can trace such a recovery for 120 cases. For these 120 cases, the average duration is 8 years (6.6 years for the 36 information/entertainment products and 8.5 years for the 84 kitchen/laundry products that experience a recovery in sales). The relative depth of the saddle is $29 \%$. The duration estimates are higher than the average duration of 5 years reported in Goldenberg, Libai and Muller (2002), while the relative depth estimates are comparable to the $32 \%$ reported in Goldenberg, Libai and Muller (2002). The average penetration at recovery is $41 \%$ with a standard deviation of 27 . 
Convergence over time. Prior research has indicated a growing convergence in the year of takeoff over time (Chandrasekaran and Tellis 2008), which may be due to the convergence in the year of commercialization or the underlying drivers over time. We find a similar "convergence" or a decrease in the standard deviation of both the year of the saddle and the time from takeoff to saddle over time for the countries that have experienced the saddle. Figure 6 plots the standard deviation in the year of the start of the saddle across product vintage (the year of first commercialization of each product category), as well as the standard deviation in the time from takeoff to saddle in years across product vintage. We see a downward trend and a dramatic drop in the standard deviation of year of saddle over time. This drop indicates that various countries increasingly experience the start of the saddle at the same time. We see a downward but more gradual trend in the standard deviation in time to saddle. This drop indicates a growing similarity across countries in the time span between takeoff and saddle.

To understand the reasons behind the start of the saddle and the subsequent recovery, we next examine the estimates of the split population hazard model, separately for the start and end of saddle.

\section{Hazard of Start of Saddle}

Prior literature has highlighted distinct differences across product classes in terms of their diffusion patterns (Chandrasekaran and Tellis 2008; Tellis, Stremersch and Yin 2003). In our sample, we too find substantial differences in the descriptive statistics and occurrence of saddles across product class. Hence, we examine the results of the split population hazard model separately by product class. Subsequently, we discuss the model's performance. The correlation matrices are in Web Appendix W2. To examine a potential concern about the independence of product categories across countries, we also examine the correlations for the year of saddle, and 
time-to-takeoff across countries. While the correlations are high, they are not close to 1 , indicating some independence across the categories.

Information/entertainment products. Table 3 gives the results of estimating the hazard model for the start of saddle. Model 1 is the split-population model for information/entertainment products. The estimated probability of never seeing a saddle is $2 \%$ for information/entertainment products. The likelihood ratios test of whether $\mathrm{c}=0$ is implemented as a boundary-value test (Jenkins, 2001). The results of the chi bar-squared test statistic from the likelihood ratio test of H0: $\mathrm{c}=0$ versus H1: $\mathrm{c}>0$ finds that the Prob $>=$ chibar $2=.06$. We find that the split population model has a lower log-likelihood (-128.5), and a lower AIC statistic (275.91) than the loglikelihood (-129.57) and AIC (277.13) reported from a standard discrete time proportional hazards model estimated on the same data. These results justify the appropriateness of the use of the split-population hazard model instead of the standard hazard model.

The results from Model 1 indicate that the coefficients of product age is positive and significantly different from zero, while age square and log age have negative and significant coefficients. The coefficient of prior saddles is not significantly different from zero.

The effect of dispersion from the mean penetration at saddle is negative and significantly different from zero. This result leads us to reject the null hypothesis and conclude in favor of the alternative hypothesis $\mathrm{H}_{\mathrm{A} 1}$ (a saddle is likely to occur during a discontinuity in the transition between the early and late markets). Hence, chasms are likely to lead to the start of a saddle for information/entertainment products. The effect of economic contraction is not significantly different from zero. This result does not find support for $\mathrm{H}_{2}$ (A saddle is likely to occur during periods of economic contractions). The coefficient of weighted patent counts is positive and 
significantly different from zero, supporting $\mathrm{H}_{3}$ (A saddle is likely to occur during times of important technological advances).

In summary, for information/entertainment products, we find support for two explanations leading to the saddle: chasms in adopter segments and technological cycles.

Kitchen/laundry products. The results for estimating the hazard of the start of the saddle for kitchen/laundry products are in Model 2 of Table 3. The estimated probability of never seeing a saddle is so small that the split population hazard model reduces to a standard proportional hazard model, which assumes $\mathrm{c}=0$. This result implies that all kitchen/laundry products are at risk for experiencing a saddle. Further, this result has face validity in that a saddle occurs in $98 \%$ of the kitchen/laundry products.

In Model 2 for kitchen/laundry products, we do not find a significant effect for product vintage or the specifications for product age. We find a positive and significant effect for prior saddles, indicating that the hazard of a saddle increases significantly with the number of prior saddles in other countries. We do not find a significant effect for dispersion from mean penetration. Hence, we do not find support for $\mathrm{H}_{\mathrm{A} 1}$. The positive and significant coefficient for economic contraction indicates that the hazard of the saddle is significantly higher during periods of economic contractions, consistent with $\mathrm{H}_{2}$. The coefficient of weighted patent counts is positive and significantly different from zero. Hence, the hazard of a saddle increases significantly during times of important technological advances, consistent with $\mathrm{H}_{3}$.

In summary, for kitchen/laundry products, we find empirical support for two explanations, controlling for duration dependency and cross-country learning effects. 
Model performance. The likelihood ratio tests and consistency of the model with the hypotheses provide support for the validity of the model. In addition, we present the results of out-of-sample predictive validity.

Out-of-sample prediction. We use a jackknife approach (similar to Golder and Tellis 1997) to ascertain the out-of-sample predictive validity of the hazard model, in the following way. We re-estimate Equation 1 with the variables showing significant effects, $\mathrm{n}$ times, for each of the $\mathrm{n}$ products that see a saddle, each time excluding one product. Then, we use the estimated parameters of the model to predict the hazard of the start of the saddle for the excluded product. The linear prediction is based on the value of the independent variables of the excluded product for that year and country. We determine the estimated year of the start of the saddle to be when the probability of no saddle (the survival probability) falls below $60 \%$. The estimate for survival probability $S_{\text {it }}$ after 1 year is $\left(1-\mathrm{hi}_{1}\right)$, after 2 years is $\left(1-\mathrm{hi}_{1}\right) .\left(1-\mathrm{hi}_{2}\right)$ and so on $($ Golder and Tellis 1997). Recall that we use a split population hazard model. For this model, we account for the split population probability by refining the survival probability as $\mathrm{c}+(1-\mathrm{c}) * \mathrm{~S}_{\mathrm{it}}$, where $\mathrm{c}$ is computed from each iteration of the estimation.

Using this approach, we make a prediction for the start of the saddle, for each productcountry combination. We compute the mean absolute deviation (MAD) in start of the saddle based on the differences between the predicted year and actual year of the start of the saddle across these product-country combinations.

We carry out this analysis for 4 recent products in 19 countries, which actually experience a saddle. The mean absolute deviation in predicted start of the saddle is 2.4 years. This error is comparable to similar out-of-sample predictions hazard models, such as 2 years in Golder and Tellis (1997) and 2.5 years in Srinivasan, Lilien and Rangaswamy (2005). 


\section{Hazard of Recovery}

The analysis of the hazard of recovery uses the 148 product-country combinations that experience the start of the saddle. We observe a recovery in 120 product-country combinations. Once again, we run the split population hazard model separately by product class. We control for the effects of time using three variables- "time since the start of the saddle" to account for duration dependence, the "year of commercialization" of a product in a country, and the "time from commercialization to saddle" to account for any dependence of duration with the prior event. We control for cross-country learning effects by including a variable "prior recoveries", which is the number of recoveries that occur in the previous year in other countries for each product. We examine the impact of business cycles and technological cycles, using the measures described previously (for business cycles, we use the variable "economic expansion", as opposed to "economic contraction") for ease of exposition.

Table 4 gives the estimates of the model for recovery for information/entertainment and kitchen/laundry products. For information/entertainment products (Model 3), all three time indicators are significantly different from zero. Time since the start of saddle has a positive and significant coefficient. This result indicates that as the time since the start of the saddle increases, the product is more likely to see a recovery. The coefficient of year of commercialization is negative and significantly different from zero. This result indicates a recovery is less likely within the observation period for those products that were commercialized later. Both these results are validated by the high censoring in recovery for newly introduced information/entertainment products. For instance, in the case of the DVD player, we observe a recovery in just one out of ten countries in which the saddle starts. The coefficient of time from commercialization to saddle is negative and significant, indicating that as the time to saddle 
decreases, the hazard of recovery increases. The estimate for prior recoveries is positive and significant, indicating that a prior recovery in another country may trigger a recovery in the focal country. The coefficient of economic expansion is not significantly different from zero. The coefficient for weighted patent counts is significant and positive, indicating that significant technological advances that occur during the saddle triggers recovery. Note however that this variable has a positive sign for both the start of the saddle, and the recovery, contrary to what may be expected. We discuss this result in a subsequent section.

Further, the estimate of $\mathrm{c}$ is 0.11 , indicating that $11 \%$ of the product-country combinations may never experience a recovery in sales. The results of the chi bar-squared test statistic from the likelihood ratio test of H0: $c=0$ versus H1: $c>0$ finds that the Prob $>=$ chibar2 $=0.03$. For example, VCRs in Portugal and Spain experience some growth after the start of the saddle, but never recover their initial peaks. Both products experience a decline in product sales by the end of the observation period.

In contrast, for kitchen/laundry products (Model 4), we find we only gain some insight on what may drive their recovery with the variable economic expansion $(\mathrm{p}<.10)$. To provide further support for this result, $60 \%$ of the products in this category see a recovery during times of economic expansion. The estimate of $\mathrm{c}$ is close to 0 . This result implies that all kitchen/laundry products eventually experience recovery.

\section{Test of Robustness}

This section tests the robustness of the results to an alternate measure of the saddle, an alternate measure of economic contraction, an alternate hazard model specification incorporating unobserved heterogeneity, the inclusion of dummy variables and a different specification of time. 
Alternate measure of saddle. We first test the robustness of our results to an alternate measure of the start of the saddle proposed by Golder and Tellis (2004) and Stremersch and Tellis (2004), which they term as slowdown. These authors operationalize start of the saddle as the first year of two consecutive years, after takeoff, in which sales are level with, or lower than the highest previous sales. We find 159 occurrences of the event using this rule and in 25 cases $(16 \%)$, we identify an earlier year of the start of the saddle with this new measure. We rerun the regressions using this new rule for the start of the saddle. For both product classes, the split population model does not converge and we use the standard discrete time proportional hazards model. For information/entertainment products, the results (Model 1 in Web Appendix W3) show support for the chasms theory, but not the theories of economic or technological cycles. For kitchen/laundry products (Model 2 in Web Appendix W3), the results show support for all three theories. However, the measure for the start of the saddle does not require a fixed percentage drop for the saddle to occur, and hence is a weaker measure. Further, the model based on this measure is unable to detect a significant proportion where the event never occurs. Hence, our original measures provide a better test of the three theories.

Alternate measure of economic cycles. We test the robustness of the analysis to an alternate measure capturing economic cycles, based on economic growth, instead of economic contraction which was based on the Hodrick and Prescott (1997) filter. We use the percent growth rate in GDP to capture economic cycles, similar to Golder and Tellis (2004). We next create an indicator variable termed economic growth contraction for the state of the economy. We set this indicator variable to 1 , for decreases in the growth rate of GDP corresponding to contractions and 0 otherwise. A positive coefficient for this measure in the hazard model would imply that the likelihood of a saddle increases during periods of lower economic growth. The 
results for information/entertainment products indicate support for the explanations of chasms and technological cycles, similar to Table 3, as well as economic cycles (Model 3 in Web Appendix W3). For kitchen/laundry products (Model 4 in Web Appendix W3), using the discrete-time proportional hazard model, we find support for the theories of economic and technological cycles only, consistent with the prior results.

Alternative hazard model specification. We examine the robustness of the analysis of the start of the saddle to the presence of unobserved heterogeneity. Using the same data set, we estimate by maximum likelihood two discrete time proportional hazards regression models, one for kitchen/laundry products, one for information/entertainment products, incorporating a gamma mixture distribution to summarize unobserved individual heterogeneity.

Specifically the discrete time hazard rates for product-country combination $\mathrm{i}$ in each duration interval $\mathrm{t}=1, \ldots, \mathrm{t} \_\mathrm{i}$ are:

$$
h_{i t}=1-\exp \left(-\exp \left(D(t)+b X_{i t}+\log \left(e_{i}\right)\right)\right)
$$

where $X_{i t}$ is a vector of covariates, $b$ is a vector of parameters to be estimated, $D(t)$ is a function describing duration dependence in the hazard common to each $\mathrm{i}$ and $\mathrm{e}_{\mathrm{i}}$ is a Gamma distributed random variable with unit mean and variance $v=\sigma^{2}$. We specify a flexible functional form of the duration dependence as $D(t)=t+t^{2}+\log t$, consistent with Table 3 . We use the PGMHAZ procedure developed by Jenkins (1997) in STATA to estimate the models.

The results are in Models 5 and 6 in Web Appendix W3. The size of the variance of the gamma mixture distribution relative to its standard error suggests that unobserved heterogeneity is not significant in this data set. The split population models in Table 3 have lower loglikelihoods and AIC scores, as well as being able to detect the proportion of products that never experience the saddle. 
Inclusion of product-specific and regional dummies. We include product specific dummies to capture the effects of any product-specific variable not accounted for in our data (Models 7 and 8 in Web Appendix W4). The results for both information/entertainment and kitchen/laundry products remain consistent with prior results. The split population hazard model for information/entertainment products do not detect a significant proportion of cases where the saddle does not occur.

Similarly, we include region specific dummies and the results remain consistent (models 9 and 10 in Web Appendix W4). The results remain substantially similar to prior results. The split population hazard model for information/entertainment products do not detect any significant proportion of cases where the saddle do not occur.

Inclusion of a different specification of time. We test the robustness of the analysis to the inclusion of a linear specification of time $(D(t)=t)$ in the hazard model (models 11 and 12 in Web Appendix W4). The results for information/entertainment products remain consistent with prior results. We determine a $\mathrm{c}$ of $6 \%$ with a Prob $>=$ Chibar $2=.00$. The results for kitchen/laundry products are substantially similar. The coefficient of dispersion is now negative and significantly different from zero, indicating support for all three theories for kitchen/laundry products.

\section{Discussion}

This section discusses the key findings and lists the contributions, implications, and the limitations of this paper.

\section{Key Findings}

A saddle is a phenomenon characterized by a sudden, sustained, and deep drop in sales of a new product, after a period of rapid growth following takeoff, followed by a gradual recovery to the former peak. We model both turning points of the saddle. We explore the generalizability 
of the saddle across an extensive data set of 156 product-country combinations (from 10 categories across 19 countries) over several decades. This presents as yet the most comprehensive study of this phenomenon. Our key empirical findings are as follows.

1. The saddle is quite pervasive across countries. The onset of the saddle occurs in 148 of 156 product-country combinations.

2. The average time from takeoff to start of the saddle is 9 years, and average depth of the saddle is $29 \%$. The average penetration at saddle is $26 \%$ for the 52 information/entertainment products that experience a saddle, and $33 \%$ for the 96 kitchen/laundry products that experience a saddle.

3. The duration of the saddle is 6.6 years for the 36 information/entertainment products and 8.5 years for the 84 kitchen/laundry products that experience a recovery in sales.

4. There is a growing convergence in the year of the saddle and the time from takeoff to saddle over time and across countries.

5. For the start of the saddle, results support the explanations of chasms and technological cycles for information/entertainment products and the explanations of business cycles and technological cycles for kitchen/laundry products.

6. Recovery to the initial peak occurs in 120 of the 148 product-country combinations that experience a saddle, with the others being censored.

7. The results indicate that a recovery for information/entertainment products is influenced by the year of commercialization, time from the start of the saddle, time from commercialization to the start of the saddle, and technological cycles, but not economic expansions; while a recovery for kitchen/laundry products may be influenced by economic expansions. 


\section{Contributions}

Why does the saddle occur? Based on a review of the literature, we identify three key explanations for the saddle: chasms in adopter segments, business cycles, and technological cycles. For kitchen/laundry products, we find support for two explanations: business cycles and technological cycles. For information/entertainment products, we find support for two explanations: chasms in adopter segments and technological cycles.

We make an important theoretical contribution by building a common bridge across the differing explanations for the saddle. Prior research has posited conflicting explanations for the saddle. Golder and Tellis (2004) find that GDP growth, which they use to measure information cascades, has an important impact on the saddle, while Goldenberg, Libai and Muller (2002) support the chasms explanation. The latter authors also mention that technological factors may drive the saddle, but do not test this explanation. By analyzing product classes separately, we find that economic cycles, technological cycles, and chasms in adopter segments are all valid explanations, but that they have a differential impact across product classes.

The impact of business cycles on the occurrence of the saddle is significant for kitchen/laundry products but not significant for information/entertainment products. There are two probable reasons for these findings. First, kitchen/laundry products are generally higherpriced than information/entertainment products and so more susceptible to economic contractions. Second, information/entertainment products are more visible and socially significant and so less susceptible to economic contractions. We further find that for information/entertainment products, recovery is not related to periods of economic expansion. However, for kitchen/laundry products, recovery is more likely to occur during periods of economic expansion. This finding supports prior studies that have established a close 
relationship between sales and economic growth (e.g. Deleersnyder et al 2004). However, our contribution is the finding of an asymmetric impact of economic cycles on the two classes of products. Moreover, compared to the typical length of economic contractions lasting anywhere between 6 and 16 months, reported by the NBER, the duration of the saddle is substantially longer lasting on average 6.5 years for information/entertainment products and 8.5 years for kitchen/laundry products.

The impact of dispersion, capturing the communication chasm between adopter segments, seems to matter for information/entertainment products rather than kitchen/laundry products. A probable reason is that the differences in the innovativeness and characteristics across consumer adopter segments may be stronger for information/entertainment products, which tend to be high technology products. For kitchen/laundry products, which are less visible, word of mouth communication may be stronger and sustained, and hence less discontinuous.

We make an important contribution by modeling the second boundary point of the saddle: recovery. For the categories that do experience the start of a saddle, we examine whether or not recovery occurs and the factors driving such a recovery, using a second split population discrete time hazard model. The split population hazard model indicates that a full recovery may not always occur for information/entertainment products. Thus, what may appear to be a temporary saddle, may in certain conditions lead to a permanent decline in the product category. We observe this phenomenon in some instances for the VCR product category, and conjecture that the likely recovery was thwarted by the takeoff of sales of the DVD player. Similarly, our operationalization of both boundary points allows us to account for potential saddles in recent products, such as the DVD player. In the US, a lead market, our data indicates that DVD players 
have seen both the slump and the recovery. Such a recovery is widely expected in other countries, from our reading of individual countries' product reports.

Further, from a modeling perspective, our analysis indicates that it is important to account for the notion that certain products may never experience the start of a saddle, or if they do, may never experience a recovery to the former peak. Our study is the first study to use the split population model to examine these turning points in the product life cycle.

\section{Implications}

The above findings may provide managers with a better understanding on the processes that underlie diffusion in the early stages of the product life cycle. There are four main implications of these findings.

First, our study indicates that the saddle is a fairly pervasive phenomenon that affects most new products. Thus growth is not perennial. At the same time, recovery is also very likely. We provide a model to determine the hazard of these two events and a set of explanatory variables that determine what drives these events. Using the values of the independent variables for a new product and estimates of the parameters of the significant coefficients of the hazard model published here, managers can use the model to predict the hazard of the start or the end of the saddle for their own new product. In addition, this study provides statistics that indicate the occurrence, depth, and duration of the saddle. Managers can use such predictions and statistics to better plan manufacturing, inventory, and marketing for recovery from the phenomenon or to sustain continuity of new product growth.

Second, managers should be cognizant of the systematic differences between kitchen/laundry products (and perhaps other similar utilitarian products) and information/entertainment products. While product managers may worry that an economic 
recession may lead to a reversal in growth of a new product category, our analysis suggests that producers of information/entertainment products may need to worry less about the specific impact of recessions, compared to producers of kitchen/laundry appliances. However, they may need to devote more attention to generating a sustained word-of-mouth momentum. Producers and marketers of kitchen/laundry products may need to pay greater attention to the impact of economic cycles.

Third, our findings point out a dramatic convergence in some aspects of the saddle across countries. These findings coupled with earlier findings on convergence of takeoff of new products suggest increasing synchronization of new product growth across countries. We suspect that this phenomenon could result from greater globalization as well synchronization of launch strategies across countries. While global companies can hope to balance slowing sales in one country with growth in another country, simultaneous or near saddles may pose a grave challenge to new product managers, especially of kitchen/laundry products. Global marketing managers should be cognizant of saddles as well as recoveries in all countries.

Fourth, our analysis suggests that technological innovations are an important driver of the recovery from a saddle. Thus, managers should consider the importance of innovation for recovery, in addition to the traditional marketing mix variables of pricing and advertising.

\section{Limitations}

This study has some limitations. First, our dispersion measure is a heuristic that does not directly capture the discontinuities in word-of-mouth communication across adopter segments. Instead, it is a proxy that captures the location of the chasm. However, our results map on to some of the key findings from multi-segment sales diffusion models from earlier studies (e.g., Goldenberg, Libai and Muller 2002; Muller and Yogev). There is a need for in-depth surveys to 
trace and analyze such points of transitions and contribute to our understanding of chasms. Second, our data do not enable us to control for several marketing variables such as price, advertising, and distribution. Third, we do not analyze the impact of entry and exit of firms during takeoff and growth, as this data is not available across countries for this extended time period. Fourth, we could not measure information cascades directly as an explanation of the saddle. All these remain useful areas for future research. 


\section{References}

Ahuja, Gautam and Riitta Katila (2001), “Technological Acquisitions and the Innovation Performance of Acquiring Firms: A Longitudinal Study,” Strategic Management Journal, 22 (3), $197-220$.

Agarwal, Rajshree and Barry L. Bayus (2002), “The Market Evolution and Sales Takeoff of Product Innovations," Management Science, 48 (8), 1024 -1041.

Allison, Paul D. (1982), Discrete-Time Methods for the Analysis of Event History Data, In Sociological Methodology, S. Leinhardt, ed. San Francisco: Jossey-Bass.

Allison, Paul D. (1995), Survival Analysis Using SAS: A Practical Guide, Cary. NC: SAS Institute Inc.

Balcer, Yves. and Lippman, Steven A. (1984), “Technological Expectations and Adoption of Improved Technology," Journal of Economic Theory, 34, 292-318.

Bass, Frank. M. (1969), “A New Product Growth Model for Consumer Durables,” Management Science, 15 (5), 215-227.

Bemmaor, A., Yanghyuk Lee (2002), “The Impact of Heterogeneity and Ill-Conditioning on Diffusion Model Parameter Estimates," Marketing Science, 21, 209-20.

Chandrasekaran, Deepa, and Tellis, Gerard J. (2007), “A Critical Review of Marketing Research on Diffusion of New Products," in Naresh K. Malhotra, Review of Marketing Research, 3, Armonk: M.E. Sharpe, 39-80.

Chandrasekaran, Deepa, and Tellis, Gerard J. (2008), "Global Takeoff of New Products: Culture, Wealth, or Vanishing Differences,?” Marketing Science, 27, 844-860. 
Chandy, Rajesh, Brigitte Hopstaken, Om Narasimhan, and Jaideep Prabhu (2006), “From Invention to Innovation: Conversion Ability in Product Development," Journal of Marketing Research, 43 (3), 494-508.

Dekimpe, Marnik, Philip Parker, and Miklos Sarvary (1998), "Staged Estimation of International Diffusion Models: An Application to Global Cellular Telephone Adoption,” Technological Forecasting and Social Change, 57, 105-32.

Dekimpe, Marnik, Philip Parker, and Miklos Sarvary (1998), (2000a) “Global Diffusion of Technological Innovations: A Coupled-Hazard Approach,” Journal of Marketing Research, 37 (1), 47-59.

Deleersnyder, Barbara, Marnik G. Dekimpe, Jan-Benedict E. M. Steenkamp, and Peter S. H. Leeflang (2009), “The Role of National Culture in Advertising's Sensitivity to Business Cycles: An Investigation across Continents," Journal of Marketing Research, 46(5), 623-36

Deleersnyder, Barbara, Marnik G. Dekimpe, Miklos Sarvary, and Philip Parker (2004),

"Weathering Tight Economic Cycles: The Sales Evolution of Consumer Durables Over the Business Cycle," Quantitative Marketing and Economics, 2(4), 347-83.

Desiraju, Ramarao, Harikesh Nair, Pradeep Chintagunta (2004), “Diffusion of New Pharmaceutical Drugs in Developing and Developed Nations," International Journal of Research in Marketing, 21(4), 341-57.

Doyle, Peter and John Saunders (1985), “The Lead Effect of Marketing Decisions," Journal of Marketing Research, 22 (1), 54-65.

Ganesh, Jaishankar, and V. Kumar (1996), "Capturing the Cross-National Learning Effect: An Analysis of an Industrial Technology Diffusion," Journal of the Academy of Marketing Science, $24(4), 328-37$. 
Ganesh, Jaishankar, V. Kumar, and V. Subramaniam (1997) "Learning Effect in Multinational Diffusion of Consumer Durables: An Exploratory Investigation," Journal of the Academy of Marketing Science, 25 (3), 214-28.

Gatignon, Hubert, Jehoshua Eliashberg, and Thomas S. Robertson (1989) “Modeling

Multinational Diffusion Patterns: An Efficient Methodology," Marketing Science, 8 (3), 231-247.

Goldenberg, Jacob, Barak Libai, and Eitan Muller (2002), "Riding the Saddle: How Cross-

Market Communications can Create a Major Slump in Sales,” Journal of Marketing, 66 (April), $1-16$.

Goldenberg, Jacob, Barak Libai, Eitan Muller and Renana Peres (2006), "Blazing Saddles: The Early and Mainstream Markets in the High-Tech Product Life Cycle," Israel Economic Review, $4(2), 85-108$.

Golder, Peter N. and Gerard J. Tellis (1997), "Will It Ever Fly? Modeling the Takeoff of Really New Consumer Durables," Marketing Science, 16 (3), 256-70.

Golder, Peter N. and Gerard J. Tellis (1998), "Beyond Diffusion: An Affordability Model of the Growth of New Consumer Durables," Journal of Forecasting, 17 (3/4), 259-80.

Golder, Peter N. and Gerard J. Tellis (2004), “Going, Going, Gone: Cascades, Diffusion, and Turning Points of the Product Life Cycle," Marketing Science, 23 (2), 207-18.

Hauser, John, Gerard J. Tellis, and Abbie Griffin (2006), "Research on Innovation: A Review and Agenda for Marketing Science," Marketing Science, 25 (6), 687-717.

Helsen, Kristaan, Kamel Jedidi, Wayne DeSarbo (1993), “A New Approach to Country Segmentation Utilizing Multinational Diffusion Patterns," Journal of Marketing, 57(4), 60-71. Hodrick, Robert J. and Edward C. Prescott (1997), "Postwar U.S. Business Cycles: An Empirical Investigation," Journal of Money, Credit, and Banking, 29 (1), 1-16. 
Holak, Susan L., Donald R. Lehmann, and Fareena Sultan (1987), “The Role of Expectations in the Adoption of Innovative Consumer Durables: Some Preliminary Evidence," Journal of Retailing, 63 (3), 243-259.

Jenkins, S. P. (1997), “Discrete time proportional hazard regression,” Stata Technical Bulletin, $39,22-32$.

Jenkins (2001), "SPSURV: Stata Module to Fit Split Population Survival (“Cure”)

Model", http://ideas.repec.org/c/boc/bocode/s418601.html, last accessed Oct 132009.

John, George, Allen M. Weiss, and Shantanu Dutta (1999), "Marketing in Technology-Intensive Markets: Toward a Conceptual Framework”, Journal of Marketing, 63(special issue), 78-91.

Kohli, Rajeev, Donald R. Lehmann, and Jae Pae (1999), “Extent and Impact of Incubation Time in New Product Diffusion.” Journal of Product Innovation Management, 16 (2), 134-44.

Kumar., V., Jaishankar Ganesh, Raj Echambadi (1998), “Cross National Diffusion Research:

What Do We Know And How Certain Are We?", Journal of Product Innovation Management, $15,255-268$

Lamey, Lien, Barbara Deleersnyder, Marnik G. Dekimpe, and Jan-Benedict E. M. Steenkamp (2007), “How Business Cycles Contribute To Private-Label Success: Evidence from the United States and Europe," Journal of Marketing, 71(1), 1-15.

Libai, Barak, Muller, Eitan, \& Renana Peres (2009a), “The Diffusion of Services,” Journal of Marketing Research, 46(1), 163-75.

Libai, Barak, Eitan Muller, \& Renana Peres (2009b), "The Role of Within-Brand and Crossbrand Communications in Competitive Growth," Journal of Marketing, 17, 19-34 Mahajan, Vijay and Eitan Muller (1998)," When is it Worthwhile Targeting the Majority Instead of the Innovators in a New Product Launch?," Journal of Marketing Research, 488-95. 
Mahajan, Vijay, Eitan Muller and Rajendra K. Srivastava (1990), “Determination of Adopter

Products by Using Innovation Diffusion Models”, Journal of Marketing Research, 27 (1), 37-50.

Mascarenhas, Briance and David A. Aaker (1989), "Strategy over the Business Cycle,"

Strategic Management Journal, 10 (3), 199-210.

Moore, Geoffrey A. (1991), Crossing the Chasm: Marketing and Selling Technology Products to Mainstream Customers, New York: HarperCollins.

Givon, Moshe, Vijay Mahajan, and Eitan Muller (1995), "Software Piracy: Estimation of Lost Sales and the Impact on Software Diffusion,” Journal of Marketing, 59 (January), 29-37.

Muller, Eitan, and Guy Yogev (2006), "When Does the Majority Become a Majority? Empirical Analysis of the Time at Which Main Market Adopters Purchase the Bulk of Our Sales," Technological Forecasting and Social Change, 73 (10), 1107-20.

Prins, Remco and Peter C. Verhoef (2007), “Marketing Communication Drivers of Adoption Timing of a New E-Service among Existing Customers,” Journal of Marketing, 71 (2), 169.

Putsis, William P., Jr., Sridhar Balasubramanian, Edward H. Kaplan and Subrata Sen (1997), “Mixing Behavior in Cross-Country Diffusion,” Marketing Science, 16 (4), 354-369.

Rogers, Everett (1995), Diffusion of Innovations. New York: The Free Press.

Sawyer, Alan G. and J. Paul Peter (1983), “The Significance of Statistical Significance Tests in Marketing Research,” Journal of Marketing Research, 20(2), 122-133.

Schmidt, Peter and Ann D. Witte (1989), "Predicting Criminal Recidivism using 'Split Population' Survival Time Models,” Journal of Econometrics, 40(1), 141-59.

Singer, Judith D. and Willet, John B. (2003), Applied Longitudinal Data Analysis: Modelling Change And Event Occurrence, Oxford University Press: New York. 
Singer, Judith D. and Willet, John B. (1993), “It's About Time: Using Discrete-time Survival Analysis to study duration and the Timing of Events," Journal of Educational Statistics, 18 (2), $155-195$.

Sinha, Rajiv K. and Murali Chandrashekaran (1992), "A Split Hazard Model for Analyzing the Diffusion of Innovations,” Journal of Marketing Research, 29(February), 116-27.

Srinivasan, Raji, Gary Lilien and Arvind Rangaswamy (2006), “The Emergence of Dominant Designs," Journal of Marketing, 70 (April), 1-17.

Srinivasan, Raji, Arvind Rangaswamy, and Gary Lilien (2005), “Turning Adversity into Advantage: Does Proactive Marketing during a Contraction Pay Off?,” International Journal of Research in Marketing, 22(2), 109-125.

Stock, James H. and Mark W. Watson (1999), "Business Cycle Fluctuations in US Macroeconomic Time Series," Pp 3-64 in Handbook of Macroeconomics, John Taylor \& Michael Woodford, eds. Elsevier Science B.V., Amsterdam.

Stremersch, Stefan, \& Lemmens, Aurélie (2009), "Sales Growth of New Pharmaceuticals Across The Globe: The Role Of Regulatory Regimes," Marketing Science, 28(4), 690-708.

Stremersch, Stefan and Gerard J. Tellis (2004), "Understanding and Managing International Growth of New Products", International Journal of Research in Marketing, 21(4), 421-38 Stremersch, Stefan, Tellis, Gerard. J., Franses, Phillip Hans., \& Binken, Jeroen. L. G. (2007), “Indirect Network Effects in New Product Growth,” Journal of Marketing, 71(3), 52-74.

Takada, Hirokazu, and Jain, Dipak (1991), “Cross-National Analysis of Diffusion of Consumer Durable Goods in Pacific Rim Countries,” Journal of Marketing, 55 (2), 48-54.

Talukdar, Debabrata, K. Sudhir and Andrew Ainslie (2002), "Investigating New Product Diffusion across Products and Countries," Marketing Science, 21(1), 97-114. 
Tellis, Gerard J., Jaideep C. Prabhu, and Rajesh K. Chandy (2009), “Radical Innovation across Nations: The Preeminence of Corporate Culture," Journal of Marketing, 73 (1), 3-24

Tellis, Gerard J., Stefan Stremersch, and Eden Yin (2003), “The International Takeoff of New Products: the Role of Economics, Culture and Country Innovativeness," Marketing Science, 22 (2), 188-208.

Trajtenberg, Manuel (1990), “A Penny for Your Quotes: Patent Citations and the Value of Innovations," The RAND Journal of Economics, 21(1), 172-187.

Van den Bulte, Christophe (2000), "New Product Diffusion Acceleration: Measurement and Analysis," Marketing Science, 19 (4), 366-80.

Van den Bulte, Christophe, and Gary. L. Lilien (1997), "Bias and Systematic Change in the Parameter Estimates of Macro-Level Diffusion Models," Marketing Science, 16 (4), 338-53. Van den Bulte, Christophe, and Yogesh V. Joshi (2007), "New Product Diffusion with Influentials and Imitators," Marketing Science, 26 (3), 400-21.

van Everdingen, Yvonne M., Wouter B. Aghinab and Dennis Fok (2005), "Forecasting CrossPopulation Innovation Diffusion: A Bayesian Approach", International Journal of Research in Marketing, 22(3), 293-308.

Weiss, Allen M. (1994), “The Effects of Expectations on Technology Adoption: Some Empirical Evidence", The Journal of Industrial Economics, 42 (4), 341-360. 
TABLE 1

Saddle Occurrences across Products

\begin{tabular}{lccccc}
\hline Products & $\begin{array}{c}\text { Applicable } \\
\text { Cases }\end{array}$ & Start & Recovery & $\begin{array}{c}\text { Mean Year } \\
\text { Of Saddle }\end{array}$ & $\begin{array}{c}\text { Range- } \\
\text { Year Of Saddle }\end{array}$ \\
\hline Dishwashers & 16 & 16 & 15 & 1980 & 26 \\
Dryers & 18 & 17 & 14 & 1983 & 45 \\
Freezers & 15 & 15 & 13 & 1975 & 39 \\
Fridges & 14 & 14 & 14 & 1966 & 42 \\
Microwave ovens & 18 & 18 & 12 & 1993 & 19 \\
Washing Machines & 16 & 16 & 16 & 1975 & 19 \\
PCs & 15 & 15 & 15 & 1989 & 8 \\
VCRs & 15 & 15 & 11 & 1988 & 14 \\
Video cameras & 15 & 12 & 9 & 1993 & 5 \\
DVD players & 14 & 10 & 1 & 2005 & 4 \\
\hline Total & 156 & 148 & 120 & & \\
\hline
\end{tabular}


TABLE 2

Descriptive Statistics

\begin{tabular}{l|rccccc}
\hline & & $\begin{array}{c}\text { Takeoff To } \\
\text { Saddle } \\
\text { (Years) }\end{array}$ & $\begin{array}{c}\text { \% Sales } \\
\text { Decline } \\
\text { At Saddle }\end{array}$ & $\begin{array}{c}\text { Penetration } \\
\text { At Saddle }\end{array}$ & $\begin{array}{c}\text { Relative } \\
\text { Depth (\%) }\end{array}$ & $\begin{array}{c}\text { Time To } \\
\text { Recovery } \\
\text { (Years) }\end{array}$ \\
\hline Information/ & Mean & 6.76 & -16.75 & 25.81 & 32 & 6.55 \\
entertainment & SD & 2.50 & 17.05 & 21.98 & 13 & 3.45 \\
products & Count & 52 & 52 & 52 & 36 & 36 \\
\hline Kitchen/ & Mean & 10.35 & -9.88 & 32.90 & 28 & 8.43 \\
laundry & SD & 5.51 & 9.60 & 25.13 & 8 & 6.19 \\
products & Count & 96 & 96 & 96 & 84 & 83 \\
\hline \multirow{3}{*}{ Overall } & Mean & 9.09 & -12.29 & 30.40 & 29 & 7.86 \\
& SD & 4.97 & 13.08 & 24.36 & 10 & 5.56 \\
& Count & 148 & 148 & 148 & 120 & 120 \\
\hline
\end{tabular}


TABLE 3

Results of Split Population Model for Start of Saddle

\begin{tabular}{|c|c|c|c|c|}
\hline \multirow{2}{*}{$\begin{array}{l}\text { Explanatory Variables } \\
\text { Product vintage }\end{array}$} & \multicolumn{2}{|c|}{$\begin{array}{c}\text { (1) } \\
\text { Information/ } \\
\text { Entertainment Products }\end{array}$} & \multicolumn{2}{|c|}{$\begin{array}{c}(2) \\
\text { Kitchen/Laundry } \\
\text { Products } \\
\end{array}$} \\
\hline & $.038 *$ & $(1.86)$ & -.003 & $(-.50)$ \\
\hline Product age & $1.904 * * *$ & $(3.46)$ & .044 & $(.16)$ \\
\hline Age square & $-.049 * * *$ & $(-3.10)$ & -.001 & $(-.27)$ \\
\hline $\log ($ Product age $)$ & $6.133 * * *$ & $(-3.00)$ & .881 & $(.33)$ \\
\hline Economic contraction & .144 & $(.49)$ & $.820 * * *$ & $(3.61)$ \\
\hline Dispersion & $-.033 * *$ & $(-1.97)$ & -.017 & $(-1.38)$ \\
\hline Weighted patent counts & $.0004 * *$ & $(2.24)$ & $.001 * *$ & $(2.25)$ \\
\hline Prior saddles & .082 & $(.70)$ & $.220 * *$ & $(2.56)$ \\
\hline Constant & $-76.044 *$ & $(-1.91)$ & -.869 & $(-.08)$ \\
\hline Observations & 400 & & 727 & \\
\hline Log likelihood & -128.5 & & -236.1 & \\
\hline
\end{tabular}

Notes:

z-statistics in parentheses

$* * * \mathrm{p}<.01, * * \mathrm{p}<.05, * \mathrm{p}<.1$ 
TABLE 4

Results of Split Population Hazard Model for Recovery

\begin{tabular}{|c|c|c|c|c|}
\hline \multirow{2}{*}{$\begin{array}{l}\text { Explanatory Variables } \\
\text { Year of commercialization }\end{array}$} & \multicolumn{2}{|c|}{$\begin{array}{c}\text { (3) } \\
\text { Information/ } \\
\text { Entertainment Products }\end{array}$} & \multicolumn{2}{|c|}{$\begin{array}{c}\text { (4) } \\
\text { Kitchen/Laundry } \\
\text { Products } \\
\end{array}$} \\
\hline & $-.220 * * *$ & $(-2.73)$ & -.022 & $(-1.27)$ \\
\hline Time since start of saddle & $.222 * * *$ & $(3.73)$ & .009 & $(.51)$ \\
\hline Economic expansion & .253 & $(.73)$ & $.440 *$ & $(1.82)$ \\
\hline Weighted patent counts & $.0002 * *$ & $(2.54)$ & .000 & $(.04)$ \\
\hline $\begin{array}{l}\text { Time from commercialization } \\
\text { to saddle }\end{array}$ & $-.165^{* *}$ & $(-2.05)$ & -.017 & $(-.85)$ \\
\hline Prior recoveries & $.270 * *$ & $(2.44)$ & $-.341^{*}$ & $(-1.87)$ \\
\hline Constant & $433.038 * * *$ & $(2.72)$ & 4.794 & $(1.19)$ \\
\hline Observations & 362 & & 837 & \\
\hline Log likelihood & -104.3 & & -242.0 & \\
\hline
\end{tabular}




\section{FIGURE 1}

\section{Saddle in New Product Sales}

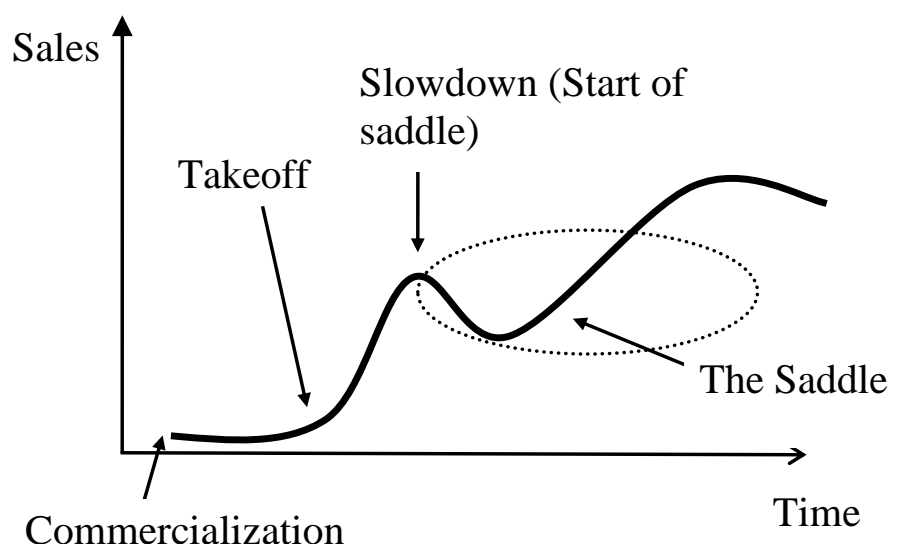


FIGURE 2

Saddles Observed in Sales of PCs and Microwave Ovens

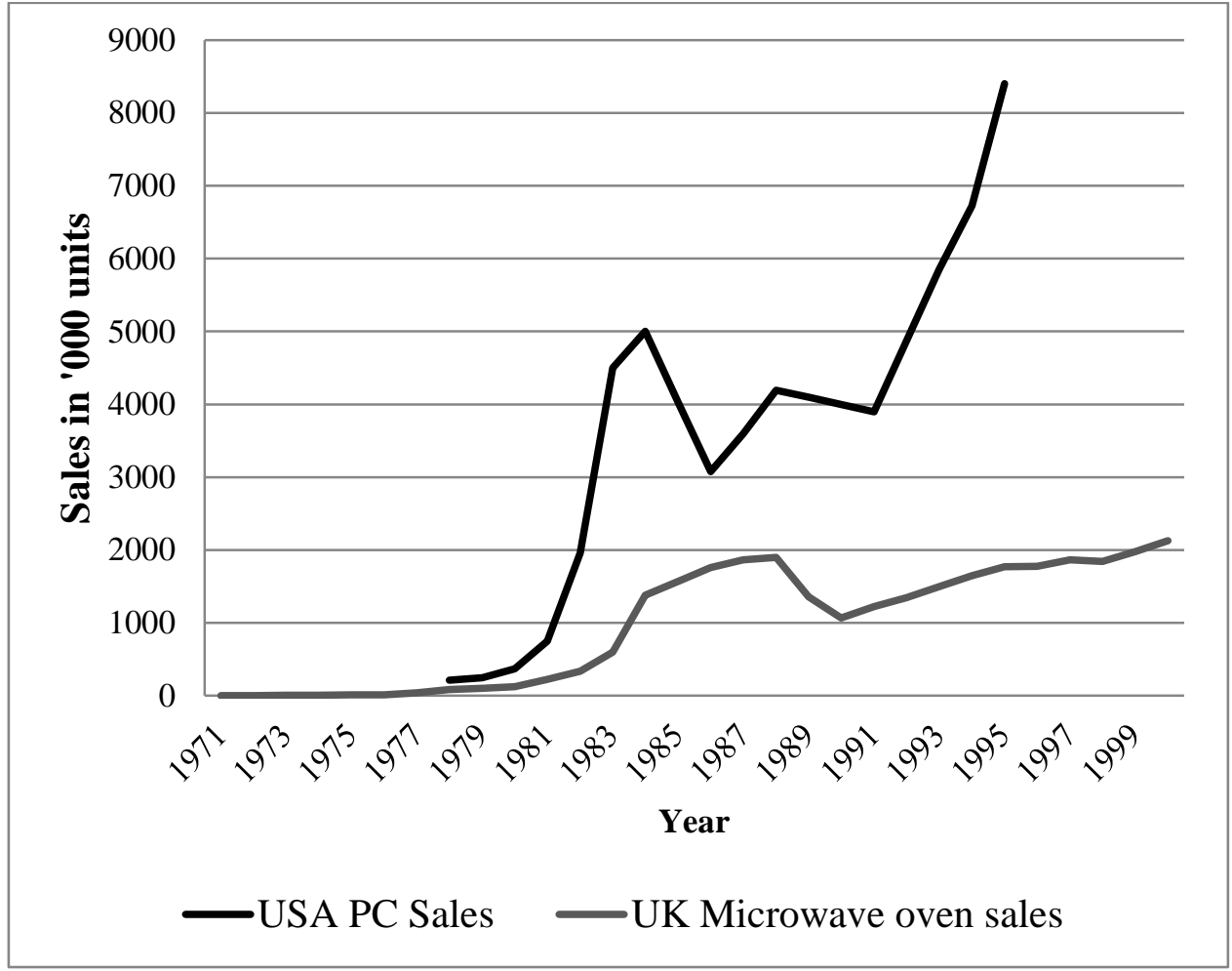


FIGURE 3

Chasms in Adopter Segments

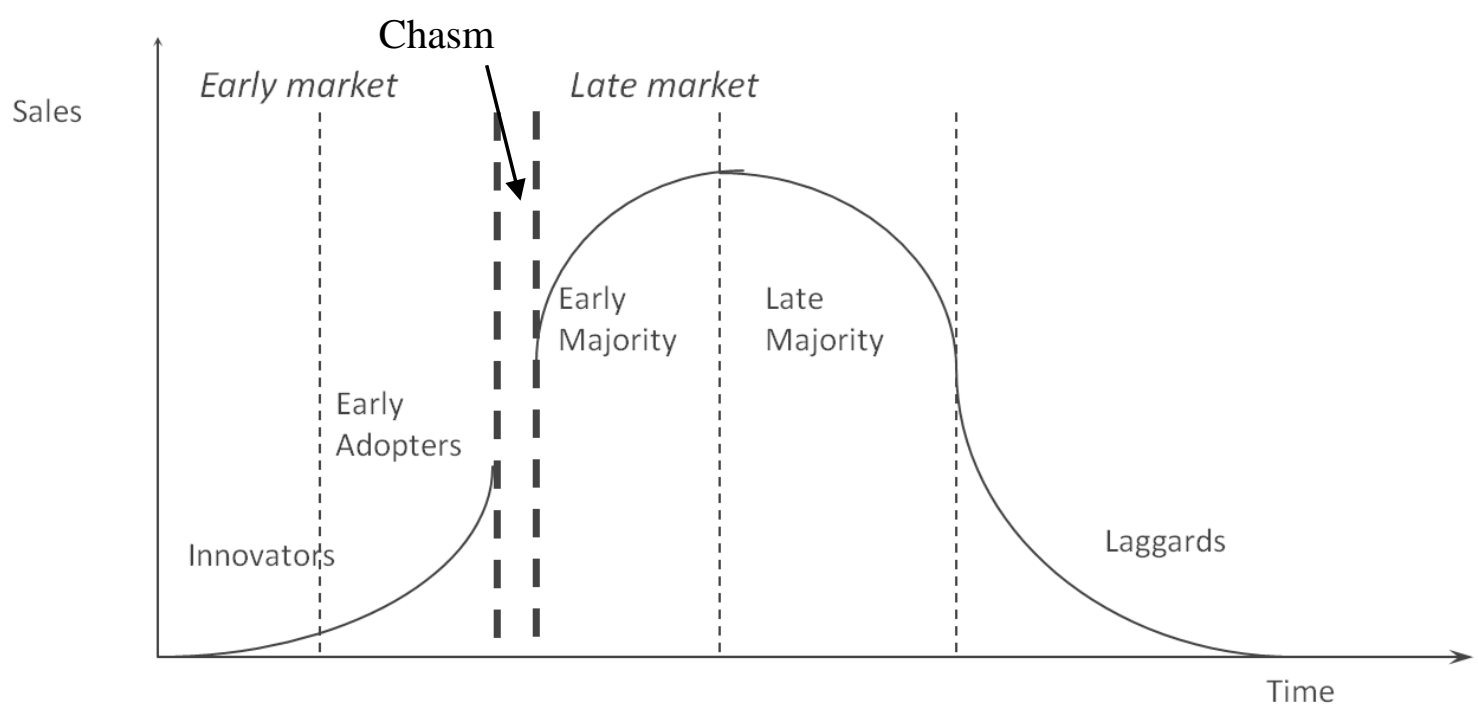


FIGURE 4

Saddle Due to a Chasm

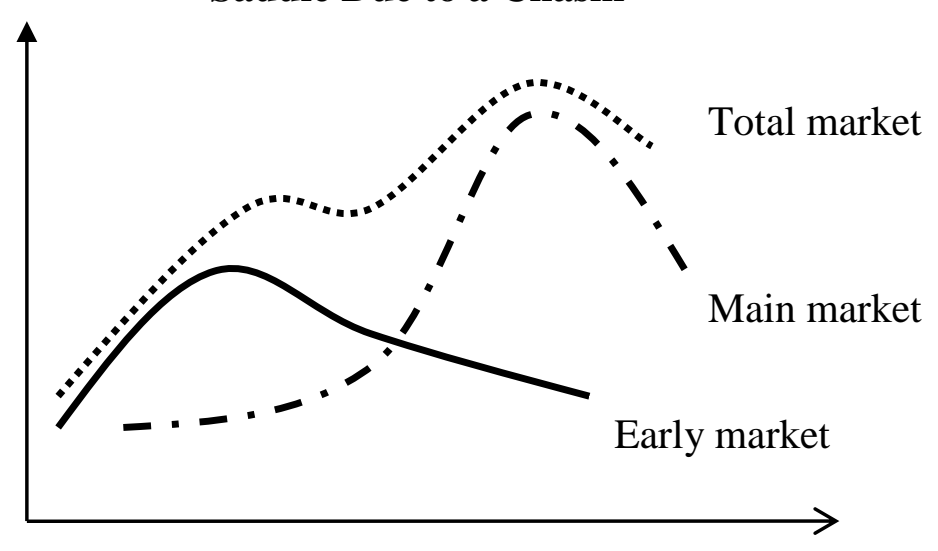


FIGURE 5

Saddle and Economic Contractions

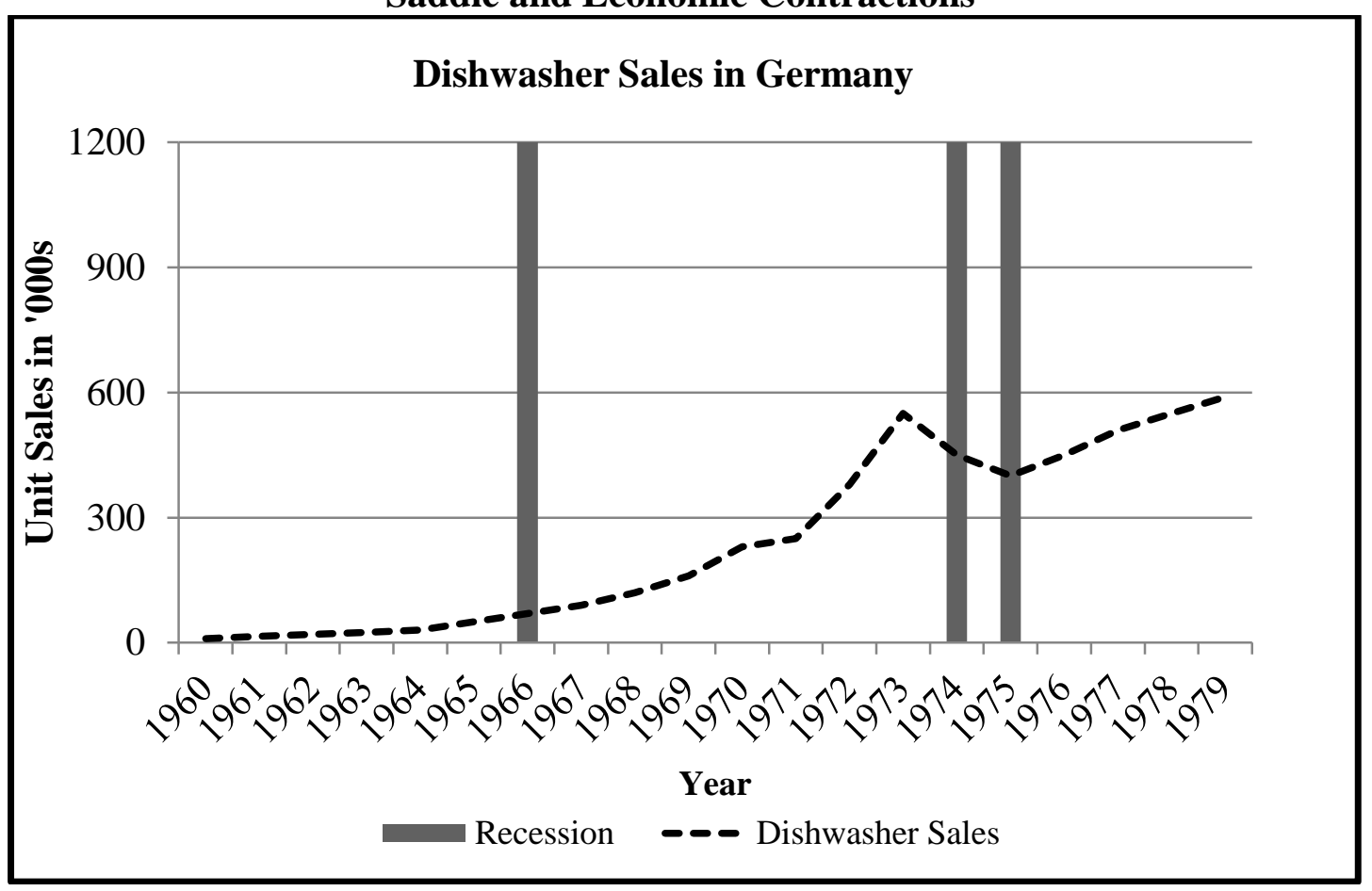


FIGURE 6

Standard Deviation of Year of Saddle and Time from Takeoff to Saddle by Vintage

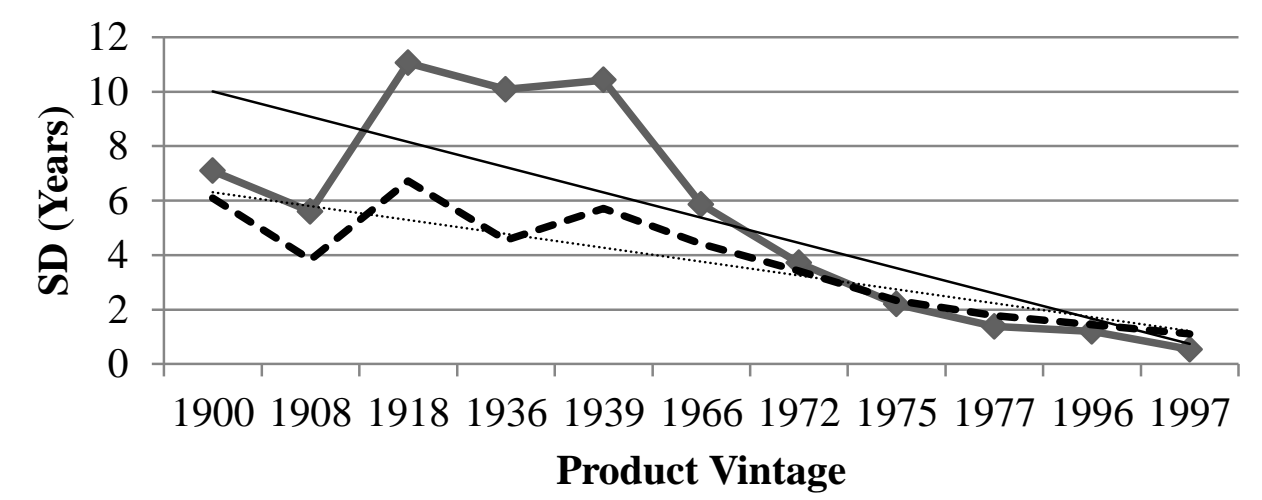

$\sim$ SD- Year of Saddle

- - SD-Time from Takeoff to saddle

— Linear (SD- Year of Saddle)

Linear (SD-Time from Takeoff to saddle) 


\section{WEB APPENDIX \\ APPENDIX W1}

OVERVIEW OF EMPIRICAL LITERATURE ON NEW PRODUCT DIFFUSION

\begin{tabular}{|c|c|c|c|c|c|c|}
\hline Authors & Sales/Adoption & Variable(s) of Interest & Method & Products & Countries & $\begin{array}{c}\text { Product- } \\
\text { Country } \\
\text { Combinations }\end{array}$ \\
\hline $\begin{array}{l}\text { Libai, Muller and Peres } \\
\text { (2009a) }\end{array}$ & Subscribers & $\begin{array}{l}\text { Diffusion parameters, } \\
\text { churn rate }\end{array}$ & $\begin{array}{l}\text { Seemingly unrelated, } \\
\text { nonlinear least squares }\end{array}$ & $\begin{array}{l}4 \text { service categories (Note: } \\
\text { multiple firms considered) }\end{array}$ & $\begin{array}{l}\text { USA/Belgium/S. } \\
\text { Korea }\end{array}$ & 7 \\
\hline Stremersch et al (2007) & Sales & Takeoff & Growth model & 9 categories & USA/ UK/Japan & 9 \\
\hline $\begin{array}{l}\text { Ganesh and Kumar } \\
\text { (1996) }\end{array}$ & $\begin{array}{l}\text { Individual store } \\
\text { level adoption }\end{array}$ & Learning coefficient & $\begin{array}{l}\text { NLS estimation of learning } \\
\text { model. }\end{array}$ & 1 industrial product & $\begin{array}{l}10 \text { European } \\
\text { countries, USA } \\
\text { and Japan }\end{array}$ & 10 \\
\hline Golder and Tellis (1998) & Sales & New product growth & Affordability model & 10 categories & USA & 10 \\
\hline $\begin{array}{l}\text { Van den Bulte and } \\
\text { Lilien (1997) }\end{array}$ & Penetration & Bass model parameters & $\begin{array}{l}\text { NLS estimation of Bass } \\
\text { model }\end{array}$ & 12 innovations & USA & 12 \\
\hline $\begin{array}{l}\text { Bemmaor and Lee } \\
(2002)\end{array}$ & Penetration & $\begin{array}{l}\text { Parameters of G/SG } \\
\text { model }\end{array}$ & Bass model; G/SG model & 12 innovations & USA & 12 \\
\hline $\begin{array}{l}\text { Van den Bulte and Joshi } \\
\text { (2007) }\end{array}$ & $\begin{array}{l}\text { Sales or } \\
\text { penetration }\end{array}$ & $\begin{array}{l}\text { Two-segment Bass } \\
\text { model parameters }\end{array}$ & $\begin{array}{l}\text { Two segment model of new } \\
\text { product growth }\end{array}$ & $\begin{array}{l}\text { Four sets of data- antibiotic } \\
\text { tetracycline; Music CDs; } 5 \\
\text { high tech products; } 8 \text { misc data } \\
\text { series }\end{array}$ & USA & $<=15$ \\
\hline Desiraju et al & Sales & $\begin{array}{l}\text { Diffusion speed, } \\
\text { penetration potential }\end{array}$ & $\begin{array}{l}\text { Hierarchical Bayesian } \\
\text { estimation of logistic } \\
\text { diffusion model } \\
\end{array}$ & 1 pharmaceutical drug category & 15 countries & 15 \\
\hline $\begin{array}{l}\text { Libai, Muller and Peres } \\
\text { (2009b) }\end{array}$ & $\begin{array}{l}\text { Number of } \\
\text { subscribers }\end{array}$ & $\begin{array}{l}\text { Takeoff time, within- } \\
\text { brand and cross-brand } \\
\text { influence }\end{array}$ & Bass-type diffusion model & $\begin{array}{l}1 \text { category - cellular phones } \\
\text { (Note: Diffusion of brands } \\
\text { within this category } \\
\text { considered) }\end{array}$ & $\begin{array}{l}16 \text { Western } \\
\text { European } \\
\text { countries }\end{array}$ & 16 \\
\hline $\begin{array}{l}\text { Deleersnyder et al } \\
\text { (2004) }\end{array}$ & Sales & $\begin{array}{l}\text { Cyclical sensitivity and } \\
\text { asymmetry }\end{array}$ & $\begin{array}{l}\text { Band pass filter and test } \\
\text { statistics }\end{array}$ & 24 consumer durables & USA & 24 \\
\hline $\begin{array}{l}\text { Agarwal and Bayus } \\
(2002)\end{array}$ & Sales & Time-to-takeoff & Proportional hazard model & 30 innovations & USA & 30 \\
\hline Golder and Tellis (2004) & Sales & Time to saddle & Proportional hazard model & 30 products & USA & 30 \\
\hline $\begin{array}{l}\text { Van Everdingen et } \\
\text { al.(2005) }\end{array}$ & Penetration & $\begin{array}{l}\text { Social system size, long } \\
\text { run penetration ceiling }\end{array}$ & $\begin{array}{l}\text { Cross-population, adaptive } \\
\text { diffusion model }\end{array}$ & $\begin{array}{l}2 \text { products- Internet access, } \\
\text { mobile telephony }\end{array}$ & $15 \mathrm{EU}$ countries & 30 \\
\hline Golder and Tellis (1997) & Sales & Time-to-takeoff & Proportional hazard model & $\begin{array}{l}31 \text { categories- consumer } \\
\text { durables and electronics }\end{array}$ & USA & 31 \\
\hline Van den Bulte (2000) & Adoption & Diffusion speed & Logistic distribution & 31 electrical products & USA & 31 \\
\hline $\begin{array}{l}\text { Kohli, Lehmann and Pae } \\
\text { (1999) }\end{array}$ & Sales & Incubation time & Bass model with NLS & $\begin{array}{l}32 \text { appliances, house wares and } \\
\text { electronics }\end{array}$ & USA & 32 \\
\hline
\end{tabular}




\begin{tabular}{|c|c|c|c|c|c|c|}
\hline $\begin{array}{l}\text { Goldenberg, Libai and } \\
\text { Muller (2002) }\end{array}$ & Sales & $\begin{array}{l}\text { Prevalence, depth and } \\
\text { duration of saddle }\end{array}$ & Cellular automata & 32 categories- electronics only & USA & 32 \\
\hline Takada and Jain (1991) & Sales & Coefficient of imitation & Bass with NLS & 8 consumer durables & $\begin{array}{l}4 \text { Pacific Rim } \\
\text { countries }\end{array}$ & 32 \\
\hline $\begin{array}{l}\text { Helsen, Jedidi and } \\
\text { DeSarbo (1993) }\end{array}$ & Sales & Country segmentation & $\begin{array}{l}\text { Latent-structure } \\
\text { methodology }\end{array}$ & 3 consumer durables & $\begin{array}{l}12 \text { countries- } \\
\text { Western Europe, } \\
\text { US and Japan }\end{array}$ & 36 \\
\hline $\begin{array}{l}\text { Ganesh, Kumar and } \\
\text { Subramaniam (1997) }\end{array}$ & Sales & Learning coefficient & $\begin{array}{l}\text { Non-linear least squares; } \\
\text { Simultaneous generalized } \\
\text { least squares }\end{array}$ & 4 consumer durables & $\begin{array}{l}16 \text { European } \\
\text { countries }\end{array}$ & $<=64$ \\
\hline $\begin{array}{l}\text { Kumar, Ganesh and } \\
\text { Echambadi (1998) }\end{array}$ & Sales & Bass model parameters & $\begin{array}{l}\text { Simultaneous estimation of } \\
\text { diffusion model parameters } \\
\text { with covariates, using GLS }\end{array}$ & 5 consumer durables & $\begin{array}{l}14 \text { European } \\
\text { countries }\end{array}$ & $<=70$ \\
\hline $\begin{array}{l}\text { Gatignon, Eliashberg } \\
\text { and Robertson (1989) }\end{array}$ & Penetration & Diffusion parameters & $\begin{array}{l}\text { Simultaneous generalized } \\
\text { least squares approach }\end{array}$ & 6 consumer durables & $\begin{array}{l}14 \text { European } \\
\text { countries }\end{array}$ & 84 \\
\hline $\begin{array}{l}\text { Tellis, Stremersch and } \\
\text { Yin (2003) }\end{array}$ & $\begin{array}{l}\text { Sales and } \\
\text { penetration }\end{array}$ & Time-to-takeoff & Parametric hazard model & 10 products & $\begin{array}{l}16 \text { European } \\
\text { countries }\end{array}$ & 137 \\
\hline This study & $\begin{array}{l}\text { Sales and } \\
\text { penetration }\end{array}$ & Start and end of saddle & $\begin{array}{l}\text { Discrete time hazard model } \\
\text { with split population } \\
\text { duration }\end{array}$ & $\begin{array}{l}10 \text { categories- consumer } \\
\text { durables and consumer } \\
\text { electronics }\end{array}$ & $\begin{array}{l}19 \text { countries- } \\
\text { Western } \\
\text { Europe, US, } \\
\text { Japan and } \\
\text { Canada }\end{array}$ & 156 \\
\hline $\begin{array}{l}\text { Stremersch and Tellis } \\
\text { (2004) }\end{array}$ & $\begin{array}{l}\text { Sales and } \\
\text { penetration }\end{array}$ & $\begin{array}{l}\text { Duration and growth } \\
\text { rate of growth stage }\end{array}$ & Parametric hazard model & 10 products & $\begin{array}{l}16 \text { European } \\
\text { countries }\end{array}$ & 160 \\
\hline $\begin{array}{l}\text { Dekimpe, Parker and } \\
\text { Sarvary (2000) }\end{array}$ & Duration & Transition rate & Coupled hazard approach & 1 service & 160 countries & 160 \\
\hline $\begin{array}{l}\text { Talukdar, Sudhir, } \\
\text { Ainslie (2002) }\end{array}$ & Sales only & $\begin{array}{l}\text { Parameters of Bass } \\
\text { model } p, q \text { and } m\end{array}$ & $\begin{array}{l}\text { Nonlinear Bass model with } \\
\text { Hierarchical Bayesian } \\
\text { estimation }\end{array}$ & 6 consumer durables & $\begin{array}{l}31 \text { developing } \\
\text { and developed } \\
\text { countries }\end{array}$ & Up to 186 \\
\hline $\begin{array}{l}\text { Dekimpe, Parker, } \\
\text { Sarvary (1998) }\end{array}$ & Penetration & Social system ceiling & Staged estimation procedure & 1 category- cell phone & 184 countries & 184 \\
\hline $\begin{array}{l}\text { Van Everdingen, } \\
\text { Stremersch and Fok } \\
(2009)\end{array}$ & Penetration & Takeoff & Discrete-time duration model & 8 products & 55 countries & 308 \\
\hline $\begin{array}{l}\text { Chandrasekaran and } \\
\text { Tellis (2008) }\end{array}$ & Penetration & Time to takeoff & $\begin{array}{l}\text { Accelerated failure time } \\
\text { hazard model }\end{array}$ & $\begin{array}{l}16 \text { categories- consumer } \\
\text { durables and electronics }\end{array}$ & $\begin{array}{l}31 \text { developing } \\
\text { and developed } \\
\text { countries }\end{array}$ & 430 \\
\hline $\begin{array}{l}\text { Stremersch and } \\
\text { Lemmens (2009) }\end{array}$ & Sales & Drug sales growth & $\begin{array}{l}\text { Time-varying coefficient } \\
\text { model }\end{array}$ & 15 new molecules & 34 countries & 510 \\
\hline Sood and Tellis (2009) & Penetration & Market penetration & Functional regression & 20 categories & $\begin{array}{l}\text { Multiple } \\
\text { countries }\end{array}$ & 760 \\
\hline
\end{tabular}

Note: Meta-analytic studies are excluded from these comparisons 
APPENDIX W2

CORRELATION MATRIX

\begin{tabular}{|c|c|c|c|c|c|c|}
\hline Variables & Event & $\begin{array}{l}\text { Product } \\
\text { Vintage }\end{array}$ & Product Age & $\begin{array}{c}\text { Economic } \\
\text { Contraction }\end{array}$ & Dispersion & $\begin{array}{c}\text { Prior } \\
\text { Saddles }\end{array}$ \\
\hline \multicolumn{7}{|c|}{ Information/Entertainment Products } \\
\hline Event & 1.00 & & & & & \\
\hline Product vintage & -.01 & 1.00 & & & & \\
\hline Product age & .19 & -.10 & 1.00 & & & \\
\hline Economic contraction & .03 & .14 & .00 & 1.00 & & \\
\hline Dispersion & -.16 & .61 & -.24 & .17 & 1.00 & \\
\hline Prior saddles & .25 & -.02 & .22 & -.05 & -.29 & 1.00 \\
\hline Weighted patent counts & .19 & -.09 & .10 & .05 & -.41 & .32 \\
\hline \multicolumn{7}{|l|}{ Kitchen/Laundry Products } \\
\hline Event & 1.00 & & & & & \\
\hline Product vintage & -.02 & 1.00 & & & & \\
\hline Product age & .14 & -.06 & 1.00 & & & \\
\hline Economic contraction & .14 & -.06 & .06 & 1.00 & & \\
\hline Dispersion & -.08 & .27 & -.30 & -.03 & 1.00 & \\
\hline Prior saddles & .11 & .04 & -.02 & .03 & -.00 & 1.00 \\
\hline Weighted patent counts & .07 & .47 & -.04 & -.03 & .32 & .19 \\
\hline
\end{tabular}


APPENDIX W3

ROBUSTNESS CHECKS

\begin{tabular}{|c|c|c|c|c|c|c|}
\hline Explanatory Variables & $\begin{array}{c}(1) \\
(\mathbf{I} / \mathbf{E})\end{array}$ & $\begin{array}{c}(2) \\
(\mathbf{K} / \mathbf{L})\end{array}$ & $\begin{array}{c}(3) \\
(\mathbf{I} / \mathbf{E})\end{array}$ & $\begin{array}{c}(4) \\
(\mathbf{K} / \mathbf{L})\end{array}$ & $\begin{array}{c}(5) \\
(\mathbf{I} / \mathbf{E})\end{array}$ & $\begin{array}{c}(6) \\
(\mathbf{K} / \mathbf{L})\end{array}$ \\
\hline Product age & $1.375^{* *}$ & .087 & $1.950 * * *$ & .038 & $1.930 * * *$ & .043 \\
\hline Age square & $-.041 * *$ & -.001 & $-.050 * * *$ & -.001 & $-.052 * * *$ & -.000 \\
\hline Log (product age) & -3.926 & .533 & $-6.412 * * *$ & .878 & $-6.049 * * *$ & .882 \\
\hline Product vintage & $.035 * *$ & -.001 & $.041 *$ & -.002 & .030 & -.002 \\
\hline Economic contraction & .305 & $.769 * * *$ & & & .233 & $.820 * * *$ \\
\hline Dispersion & $-.059 * * *$ & $-.030 * *$ & $-.035 * *$ & -.018 & $-.034 *$ & -.017 \\
\hline Weighted patent counts & -.000 & $.001 * *$ & $.0003 * *$ & $.001 *$ & .0002 & $.001 * *$ \\
\hline Prior saddles & .077 & $.219 * * *$ & .100 & $.197 * *$ & .140 & $.219 * *$ \\
\hline Change in economic growth & & & $.657 * *$ & $.760 * * *$ & & \\
\hline Constant & $-71.048 * *$ & -3.427 & $-83.576 * *$ & -1.759 & -62.32 & -88.62 \\
\hline Observations & 453 & 620 & 400 & 727 & 400 & 727 \\
\hline Log likelihood & -152.0 & -217.6 & -124.9 & -237.5 & -129.6 & -236.1 \\
\hline
\end{tabular}

Notes:

$* * * \mathrm{p}<.01, * * \mathrm{p}<.05, * \mathrm{p}<.1$

$\mathrm{I} / \mathrm{E}$ refers to Information/Entertainment products and $\mathrm{K} / \mathrm{L}$ refers to Kitchen/Laundry products 
APPENDIX W4

ROBUSTNESS CHECKS (CONTINUED)

\begin{tabular}{|c|c|c|c|c|c|c|}
\hline Explanatory Variables & $\begin{array}{c}(7) \\
(\mathbf{I} / \mathbf{E})^{\mathbf{a}}\end{array}$ & $\begin{array}{c}(8) \\
(\mathbf{K} / \mathbf{L})^{\mathbf{a}}\end{array}$ & $\begin{array}{c}(9) \\
(\mathbf{I} / \mathbf{E})^{\mathbf{a}}\end{array}$ & $\begin{array}{c}(10) \\
(\mathbf{K} / \mathbf{L})^{\mathbf{a}}\end{array}$ & $\begin{array}{l}(11) \\
(\mathbf{I} / \mathbf{E})\end{array}$ & $\begin{array}{c}(12) \\
(\mathbf{K} / \mathbf{L})\end{array}$ \\
\hline Product vintage & .032 & -.007 & $.035 *$ & .001 & $.053 * *$ & -.002 \\
\hline Product age & $1.278 * *$ & .125 & $1.853 * * *$ & .149 & $.304 * * *$ & $.046 * * *$ \\
\hline Age square & -.029 & -.002 & $-.047 * * *$ & -.002 & & \\
\hline Log(Product age $)$ & $-4.673 * *$ & .390 & $-5.868 * * *$ & .350 & & \\
\hline Economic contraction & .242 & $.864 * * *$ & .216 & $.823 * * *$ & .233 & $.811 * * *$ \\
\hline Dispersion & $-.050 * * *$ & -.013 & $-.033 *$ & -.015 & $-.043 * *$ & $-.023 * *$ \\
\hline Weighted patent counts & $.001 * *$ & $.002 * *$ & $.001 * *$ & .001 & $.0004 * *$ & $.001 * *$ \\
\hline Prior saddles & .009 & $.214 * *$ & .148 & $.212 * *$ & -.007 & $.228 * * *$ \\
\hline Constant & -63.235 & 7.890 & $-69.883 *$ & -7.215 & $-108.905 * * *$ & -.544 \\
\hline Observations & 400 & 727 & 400 & 727 & 402 & 727 \\
\hline Log likelihood & -125.8 & -233.3 & -123.3 & -232.6 & -129.9 & -237.2 \\
\hline
\end{tabular}

${ }^{a}$ Product and regional dummies are not included

Notes:

Z-statistics in parentheses

$* * * \mathrm{p}<0.01, * * \mathrm{p}<0.05, * \mathrm{p}<0.1$

$\mathrm{I} / \mathrm{E}$ refers to Information/Entertainment products and K/L refers to Kitchen/Laundry products 